\title{
Effect of Clay on Internal Erosion of Clay-Sand-Gravel Mixture
}

\author{
Chen Liang, ${ }^{1,2}$ Cai Guo-dong $\mathbb{D}^{1,2}$ Gu Jia-hui, ${ }^{1,2}$ Tan Ye-fei, ${ }^{3,4}$ Chen Cheng, ${ }^{1,2}$ \\ and Yin Zi-xue ${ }^{1,2}$ \\ ${ }^{1}$ Key Laboratory of Ministry of Education for Geomechanics and Embankment Engineering, Hohai University, Nanjing, China \\ ${ }^{2}$ College of Civil and Transportation Engineering, Hohai University, Nanjing, China \\ ${ }^{3}$ Nanjing Hydraulic Research Institute, Nanjing, China \\ ${ }^{4}$ Sluice Safety Management Center of Ministry of Water Resources, Nanjing, China
}

Correspondence should be addressed to Cai Guo-dong; geocgd1996@163.com

Received 29 May 2020; Revised 22 July 2020; Accepted 11 August 2020; Published 26 August 2020

Academic Editor: Qiang Tang

Copyright (c) 2020 Chen Liang et al. This is an open access article distributed under the Creative Commons Attribution License, which permits unrestricted use, distribution, and reproduction in any medium, provided the original work is properly cited.

\begin{abstract}
In this study, a one-dimensional seepage test apparatus was used to investigate the effect of clay on the critical hydraulic gradient, hydraulic conductivity, migration of fine particles in soil, and percentage of fine particle loss during the internal erosion of claysand-gravel mixture, compared with clean gravel. The critical hydraulic gradient and fine sand loss percentage of the clay-sandgravel mixture decreased, and critical flow velocity and the hydraulic conductivity increased. Six clay-sand-gravel mixture samples with different clay contents were used to evaluate the effect of different clay contents on internal erosion. As the percentage of clay mass to fine particle mass increases from $0 \%$ to $25 \%$, the critical hydraulic gradient of soil samples decreases by nearly half and the fine sand loss percentage decreases from $13.73 \%$ to $3.48 \%$. Overall, clay has a significant effect on the development of internal erosion of clay-sand-gravel mixture. And attention should be paid in engineering project; clay-sand-gravel mixture with a small amount of clay is more likely to be damaged than clean gravel.
\end{abstract}

\section{Introduction}

Presently, China has $14,500 \mathrm{~km}$ of seawall, but the length conforming to standards is only $6181.8 \mathrm{~km}$. Owing to the extremely torrential rainfall generated by typhoons, and the soils in foundations and seawalls being gap-graded, many seawalls face potential safety hazards. One such problem is internal erosion, which can undermine the strength and stability of the granular skeletons of coastal waterfront structures and their foundations [1-3]. In the literature, the term "internal erosion" usually refers to the detachment of fine particles from the main soil structure due to the mechanical or chemical action of fluids. "Internal erosion" usually includes "suffusion" and "piping." During the suffusion process, fine particles are eroded by seepage through the pores between the larger particles, leaving the coarse framework, while piping is like gradual erosion and transportation of fine particles along the flow path. Suffusion and piping are always coupled. The term "internal erosion" commonly used in this paper refers to the target phenomenon, in which small particles are swept away by seepage from the pores between coarse particles leaving behind soil skeletons, and "internal erosion" often occurs in cohesionless sand and gravel. In recent years, the rise of sea level and the frequent occurrence of extreme weather events, such as typhoons, have resulted in increasingly more attention being directed toward the internal erosion and damage of seawalls.

Many studies [4-8] have reported that the potential for the internal erosion of soil is mainly controlled by the soil's grain size distribution. Generally, it is accepted that gapgraded granular soils and broadly graded soils with a flat slope in the fine portion and a steep slope in the coarse portion are often internally unstable. Numerous researchers have reported that the initiation of internal erosion in potentially unstable soil is triggered when the hydrodynamic forces induced by the seepage flow in the soil grains exceed a critical threshold $[2,9,10]$. Skempton and Brogan [11] 
proposed a relationship between the onset of suffusion and the increase of hydraulic conductivity and characterised this hydraulic loading threshold using the hydraulic gradient and flow velocity, which are termed as the critical hydraulic gradient and critical flow velocity, respectively. However, various studies have reported that some detached particles can induce soil blockage, accompanied by the decrease of hydraulic conductivity [12-15]. Several studies have been conducted to investigate the mechanical behavior of soils subjected to internal erosion by controlling the hydraulic gradient to simulate the erosion process [16-19]. In addition to these experimental studies, various attempts have been made to model the internal erosion based on analytical and numerical approaches [20-23].

Most research results with regard to internal erosion have focused on clean sand or clean gravel. However, in some seawall constructions in China, such as the land reclamation of Ganyu port in Lianyungang, the hydraulic filling method was applied by dredging the original sand and clay interbedded layers, leading to the formation of sandclay mixtures [24]. Various studies [25-27] have reported that the compressibility of compacted clay-sand mixtures is governed by the sand fraction when the sand fraction reaches a threshold and forms a sand skeleton. Regarding the percolation behavior, Watabe et al. [26] found that the increase of sand fraction leads to a slight increase in hydraulic conductivity below a certain threshold, followed by a sharp increase beyond the threshold. Shayea [28] investigated the effect of different clay contents on the permeability of sand. Their results revealed that the ability of sand with low clay content to reduce the permeability coefficient is significantly greater than that of sand with high clay content. Tripathi and Viswanadham [29] reported that the percolation behavior of sand-bentonite mixtures is controlled by the initial saturation process, testing method, and bentonite content. The erosion of clay-sand mixture has also been studied by some researchers. Rajesh et al. [30] studied suspended load transport rates of clay-sand-gravel mixtures and indicated the bed material was detached by flow in the form of flakes if the bed material contained more than $20 \%$ clay by weight. Bendahmane et al. [31] concluded that the erosion of the structure's clay fraction was due to suffusion when the hydraulic gradient was low. Marot et al. [13] revealed that suffusion of clay of clay-sand mixture is accompanied by a clogging in the specimen that induces a drop in hydraulic conductivity.

In the abovementioned studies, researchers have conducted in-depth investigations into the internal erosion of clean sand and clean gravel. Moreover, some researchers have investigated the problem of percolation behavior and internal erosion in clay-sand mixtures and clay-sand-gravel mixtures. However, little research has been done about the effect of clay on fine sand loss and critical hydraulic gradient due to internal erosion of gravel sand-clay mixtures, which is of great significance for engineering construction and risk assessment. In construction projects, such as the reclamation of embankments, sand-gravel mixtures often contain a small clay amount, so it is particularly important to investigate the effect of clay on internal erosion of clay-sand-gravel mixtures.

\section{Materials and Test Apparatus}

Because internal erosion occurs mostly in gap-graded natural cohesionless sand and gravel soils or in low-quality artificial fills, the test material consisted of coarse particles and fine particles mixed at a certain proportion to form a gap-graded gravel sample. According to the theory proposed by Kenney in 1985 [4], the coarse particles used in the test were gravels with a particle size of 2.0 to $6.0 \mathrm{~mm}$ and specific gravity of 2.63. In this study, the fine particles included fine sand and clay. Amongst them, yellow sand was used as the fine sand; the particle size was $0.075-0.25 \mathrm{~mm}$, and the specific gravity of the sand is 2.63 . The clay was 3000 mesh kaolin; the specific gravity of kaolin is 2.60 . Table 1 shows the testing plan and the parameters of soil samples. Figure 1 presents the grain size distribution curves of test soils. The pore volume of the mixed soil is $e$, and $\alpha$ is the percentage of fine particle mass to the sample's total mass. The clay content is defined as the percentage of the clay mass of fine particle mass; the clay content is denoted as cc and is expressed as follows:

$$
\mathrm{cc}=\frac{m_{c}}{m_{s}+m_{c}}
$$

where $m_{s}$ is the fine sand mass and $m_{c}$ is the clay mass.

Constant head seepage tests with upward water flow are performed to cause internal erosion. The cylindrical test water tank is shown in Figure 2. The cylindrical test water tank is $150 \mathrm{~mm}$ in internal diameter and $350 \mathrm{~mm}$ in height. The transparent seepage cell allows for the observation of the internal erosion from the side. The upper end of the seepage cell is left open so that the erosion process can be observed from the top. Nonwoven textile is placed at the bottom of the specimen to prevent downward fine particle loss. The variation in water head within the specimen is measured by three standpipes at three different depths, $50 \mathrm{~mm}, 125 \mathrm{~mm}$, and $200 \mathrm{~mm}$. The inlet is connected to a constant water head tank, which can be raised or lowered to control the hydraulic gradient across the specimen, while the outlet is open to the atmosphere.

\section{Testing Procedure}

(1) Sample Preparation. In the samples containing clay particles, gravel and fine sand were divided into three groups: upper, middle, and bottom. First, the fine sand and clay particles were uniformly mixed; then, the coarse particles and a small amount of water were added, and adequate mixing and stirring were carried out. In the clean gravel samples, the coarse and fine particles were evenly divided into three groups, a small amount of water was added, and adequate mixing was carried out.

(2) Sample Loading and Saturation. Before loading the sample, petroleum jelly was applied to the inner wall of the plexiglass tube to prevent the sample from penetrating and causing damage along the tube wall. The bottom, middle, and upper three groups were sequentially loaded, and compaction was applied 
TABle 1: Properties of soil used in testing.

\begin{tabular}{|c|c|c|c|c|c|c|c|}
\hline Sample group & Sample no. & $\alpha / 100(\%)$ & $f_{c} / 100(\%)$ & $\mathrm{e}$ & $\mathrm{Dr}$ & $c_{u}$ & $c_{c}$ \\
\hline \multirow{3}{*}{ CFC } & CFC-1 & 10 & 10 & 0.574 & 0.5 & 14.73 & 7.08 \\
\hline & CFC-2 & 15 & 10 & 0.5 & 0.5 & 22.35 & 10.29 \\
\hline & CFC-3 & 20 & 10 & 0.4515 & 0.5 & 27.05 & 11.87 \\
\hline \multirow{3}{*}{ FC } & FC-1 & 10 & 0 & 0.574 & 0.5 & 14.73 & 7.08 \\
\hline & FC-2 & 15 & 0 & 0.5 & 0.5 & 21.38 & 9.84 \\
\hline & FC-3 & 20 & 0 & 0.4515 & 0.5 & 25.30 & 11.10 \\
\hline \multirow{6}{*}{ CS } & CS-0 & 15 & 0 & 0.5 & 0.5 & 21.38 & 9.84 \\
\hline & CS-1 & 15 & 5 & 0.5 & 0.5 & 21.83 & 10.05 \\
\hline & CS-2 & 15 & 10 & 0.5 & 0.5 & 22.35 & 10.29 \\
\hline & $\mathrm{CS}-3$ & 15 & 15 & 0.5 & 0.5 & 22.95 & 10.57 \\
\hline & $\mathrm{CS}-4$ & 15 & 20 & 0.5 & 0.5 & 23.63 & 10.88 \\
\hline & CS-5 & 15 & 25 & 0.5 & 0.5 & 24.44 & 11.25 \\
\hline
\end{tabular}

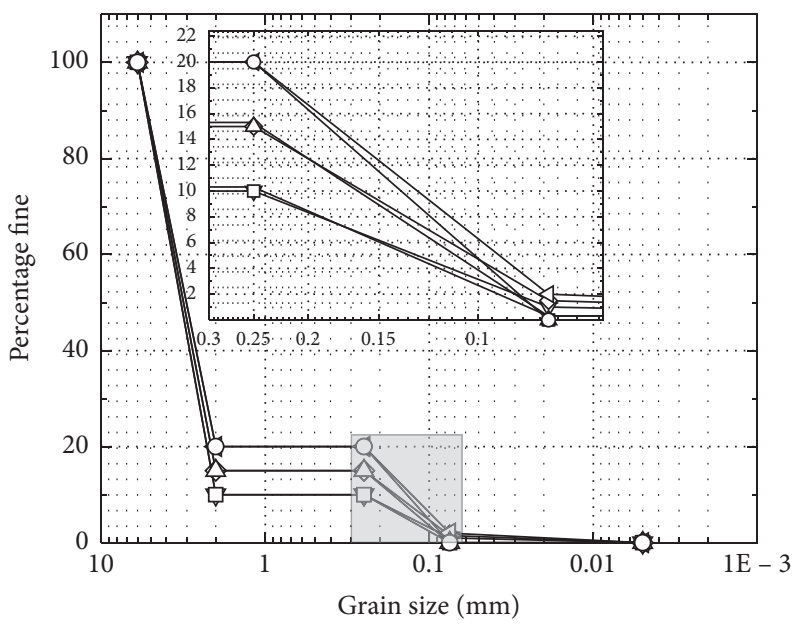

$$
\begin{array}{lll}
\neg-\text { CFC-1 } & -\square \text { FC-1 } \\
\checkmark \text { CFC-2 } & -\checkmark \text { FC-2 } \\
\checkmark \text { CFC-3 } & -\bigcirc \text { FC-3 }
\end{array}
$$

(a)

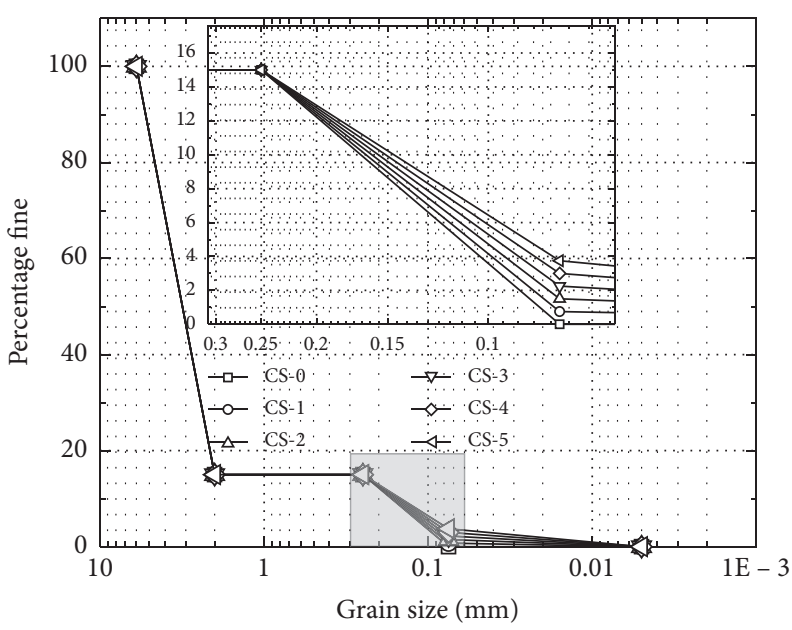

$\begin{array}{ll}-\square- & \text { CS- } 0 \\ -0 & \text { CS-1 } \\ - & \text { CS- } 2\end{array}$ $-\nabla$ CS-3 $\diamond$ CS- 4 $\triangleleft$ CS-5

(b)

FIGURE 1: Grain size distribution curve. (a) Grain size distribution curve for CFC and FC groups. (b) Grain size distribution curve for CSC group.

every $2-3 \mathrm{~cm}$. Each sample group was filled to the filling line of the corresponding height. After the sample was saturated for $24 \mathrm{~h}$, the test was conducted.

(3) Testing. The water head was slowly raised to increase the hydraulic gradient $i$ of each stage from 0.05 to 0.10 , and the water head action time of each stage was $20 \mathrm{~min}$. The pressure measuring standpipes and flow values were recorded every $5 \mathrm{~min}$, and the next water head level was raised when the two current readings remained unchanged. Test observations were carefully collected. If the water exhibited turbidity, bubbling, and fine particle beating, the head duration for this grade was appropriately extended.

(4) When a large amount of fine sand was removed from the sample surface and the flow velocity suddenly increased, it was considered that the sample was damaged and the test was concluded.

\section{Results and Discussion}

4.1. Critical Hydraulic Gradient and Critical Velocity of CFC and FC Groups. CFC samples are clay-sand-gravel mixtures and FC samples are sand-gravel mixtures (clean gravel). Both group CFC and group FC samples (i.e., CFC1 and FC1; CFC2 and FC2; CFC3 and FC3) have the same mass of fine particles, while $10 \%$ of the fine particles in CFC group are replaced by clay particles. During the test, the indoor temperature was $10^{\circ} \mathrm{C}$ and the dynamic viscosity coefficient of water $\eta=1.306 \times 10^{-6} \mathrm{~m}^{2} / \mathrm{s}$. According to the calculation formula $\operatorname{Re}=v d_{10} / \eta$, each sample had a Reynolds number $<5$ as shown in Table 2; therefore, it was considered that the water flow still complied with Darcy's law.

At the beginning of the test, owing to the small hydraulic gradient, the surface of the water body was clear and fine particle bouncing was not observed. As the water head increased, a small dancing-like movement of fine particles was observed at several locations on each side of the sample 


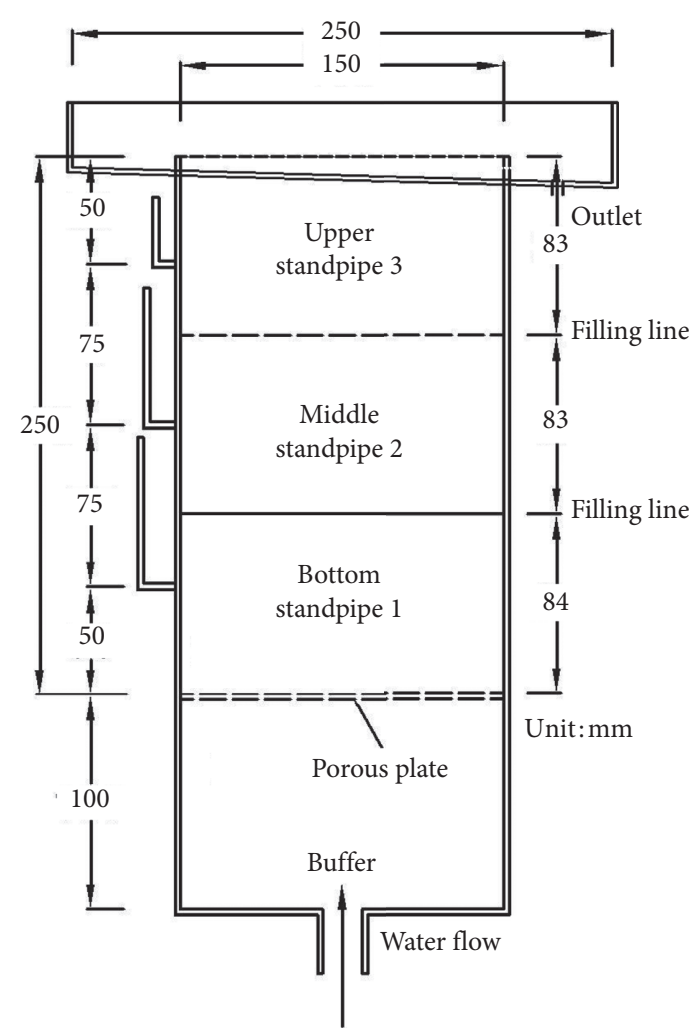

FIgURE 2: Schematic diagram of the cylindrical test tank.

TABle 2: Reynolds numbers for CFC and FC groups.

\begin{tabular}{lcccccc}
\hline & CFC-1 & FC-1 & CFC-2 & FC-2 & CFC-3 & FC-3 \\
\hline$v(\mathrm{~cm} / \mathrm{s})$ & 0.077 & 0.068 & 0.072 & 0.074 & 0.060 & 0.049 \\
$d_{10}(\mathrm{~mm})$ & 0.25 & 0.25 & 0.192 & 0.192 & 0.163 & 0.163 \\
$\operatorname{Re}$ & 0.148 & 0.131 & 0.106 & 0.108 & 0.075 & 0.061 \\
\hline
\end{tabular}

at various depths. The flow velocity of the sample slowly increased, and the clay attached to the surface of the sand particles moved under the action of the seepage water flow to overcome the force between the sand particles. The water on the sample surface became turbid and tiny flocculent particles were observed to flow out of the sample surface.

According to the experimental observations and inflection point of the flow velocity with the hydraulic gradient shown in Figure 3, when the water on the sample surface became turbid and the flow velocity slowly increased with the increase of the hydraulic gradient, it was considered that the fine particles had begun to move and blocked the pores, as shown in Figure 4(b). Here, the hydraulic gradient at the first inflection point of the curve is the blockage critical gradient, and the flow velocity at the inflection point is the blockage critical flow velocity. In Figure 3, the dashed line blockage is the connection line of the critical point of each sample, and the lower left part of the dashed line blockage is the stable seepage stage of each sample.

With the continuous increase of the external water head, the fine sand moved upwards at two or three spots on the top of the sample and then stopped. The water head continued to increase, and there was a strong general piping of fine

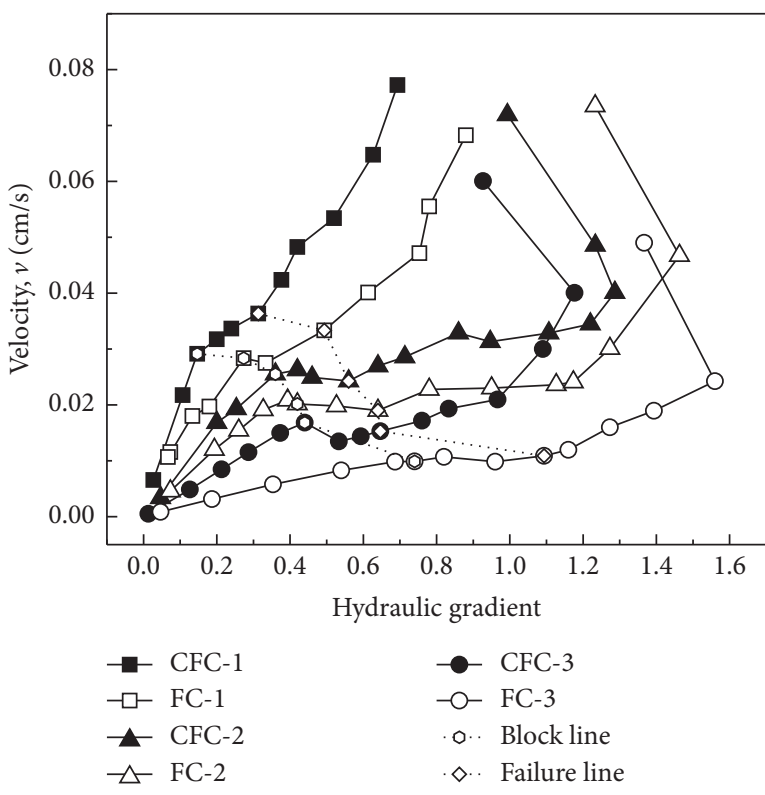

FIgURE 3: Variation of flow velocity with hydraulic gradient for $\mathrm{CFC}$ and FC groups.

particles throughout, accompanied by water flow turbidity and the rapid increase of flow velocity. Figure 5(d) shows a photograph of the sample surface after being damaged. Based on the experimental observations and the inflection point of the relationship curve between the flow velocity and the hydraulic gradient, when the increase of the flow velocity started becoming faster, the fine sand was continuously taken out of the sample, and the previously blocked pore became unblocked again, as shown in Figure 4(c). Therefore, it is considered that the soil had begun to fail. The hydraulic gradient at the second inflection point of the curve is considered as the critical hydraulic gradient of failure, and the flow velocity at the inflection point is the failure critical velocity. In Figure 3, the dashed line failure is the line connecting the critical failure points of each sample. The area between the dashed line blockage and the dashed line failure is defined as the particle blockage stage. The area to the right of the dashed line failure is defined as the seepage failure stage. Under the high hydraulic gradient, CFC-1, FC-1, CFC-2, and FC-2 are completely destroyed under the action of long-time seepage, so the sample cannot bear the high hydraulic gradient and the hydraulic gradient decreases.

As presented in Table 3, with the same fine particle content, the critical hydraulic gradient of group CFC was smaller than the critical hydraulic gradient of group FC, and the critical flow velocity of group CFC was greater than the critical flow velocity of group FC. The blockage critical hydraulic gradient of the FC- 1 sample was 0.27 , while that of the CFC sample was only 0.15 . Because the fine sand in group CFC was partially replaced by clay with equal mass, the clean gravel became a clay-sand-gravel mixture, as shown in Figure 6. Because the particle size of the clay particles was much smaller than that of fine sand and gravel, when the clay content was low, the clay particles did not completely occupy the pores between the sand particles and 


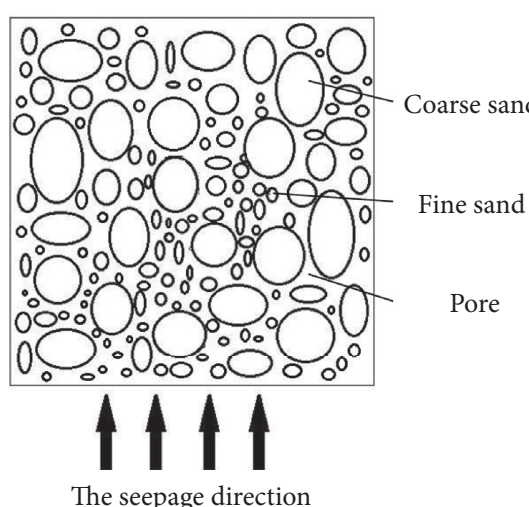

(a)

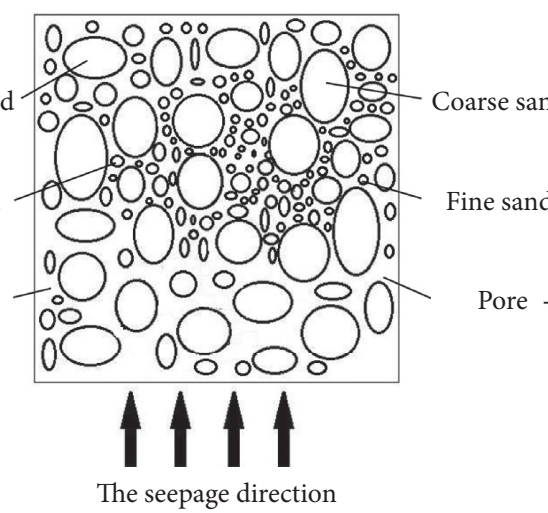

(b)

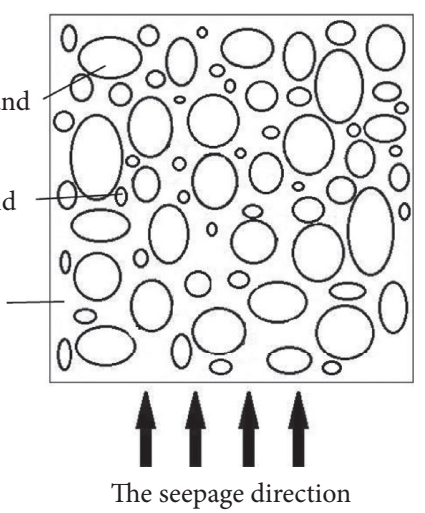

(c)

FIgURE 4: Schematic diagram of different seepage stages. (a) The stable seepage stage. (b) The particle blockage stage. (c) The seepage failure stage.

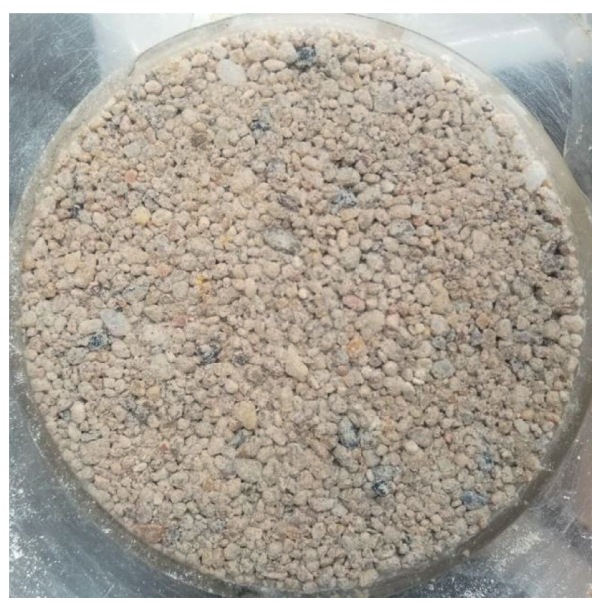

(a)

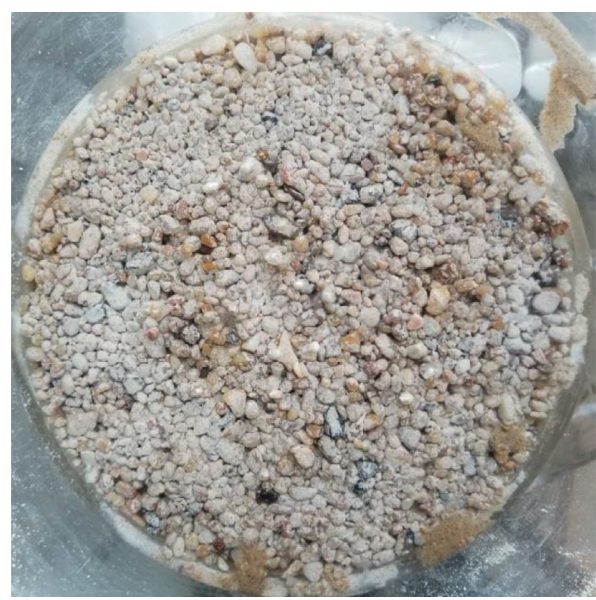

(c)

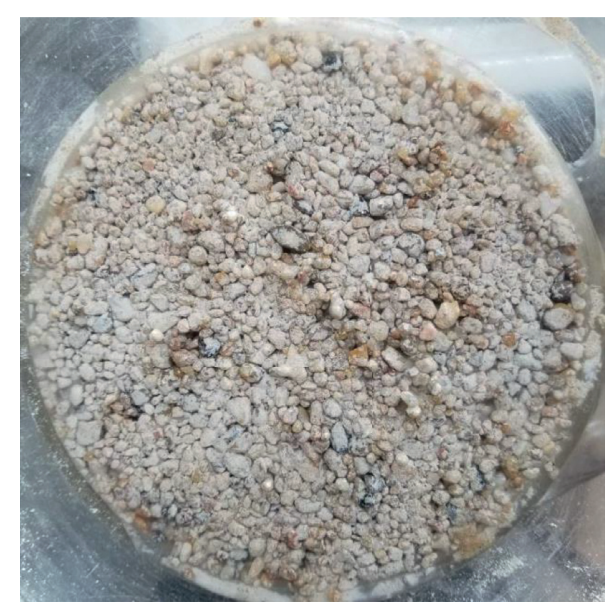

(b)

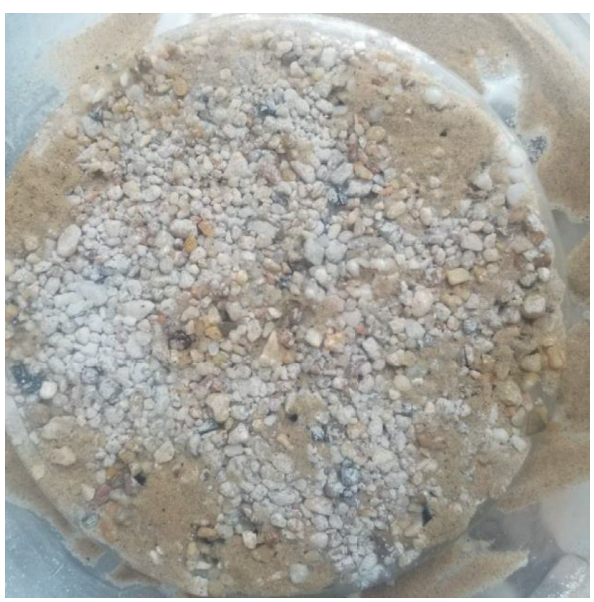

(d)

Figure 5: Observed particle migrations from top (specimen CS-3). (a) Stable seepage $i=0.16$. (b) Seepage development $i=0.46$. (c) Seepage failure $i=0.71$. (d) Completely destroyed $i=1.22$.

the gravel particles, and most of them stuck on the surface of the gravel particles and formed a membrane of clay particles, which enlarged the pipelines pores of sand migration. According to the theory proposed by Thevanayagam [32], when the clay content is low and the dry density of the sand grain and gravel grain group is the same or similar to the dry density of the clay grain, the complex particle microstructure can be simplified and considered to consist 
TABLe 3: Critical flow velocity and critical hydraulic gradient of CFC and FC groups.

\begin{tabular}{|c|c|c|c|c|c|c|}
\hline & CFC-1 & FC-1 & CFC-2 & FC-2 & CFC-3 & FC-3 \\
\hline Blockage critical hydraulic gradient & 0.15 & 0.27 & 0.36 & 0.42 & 0.44 & 0.74 \\
\hline Blockage critical velocity $(\mathrm{cm} / \mathrm{s})$ & 0.0291 & 0.284 & 0.0251 & 0.0202 & 0.017 & 0.01 \\
\hline Failure critical hydraulic gradient & 0.31 & 0.49 & 0.56 & 0.64 & 0.59 & 1.09 \\
\hline Failure critical velocity $(\mathrm{cm} / \mathrm{s})$ & 0.036 & 0.033 & 0.0243 & 0.0194 & 0.01437 & 0.0109 \\
\hline
\end{tabular}

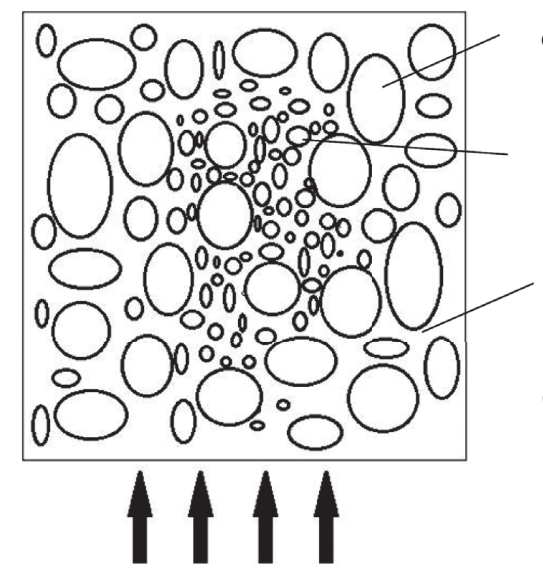

The seepage direction

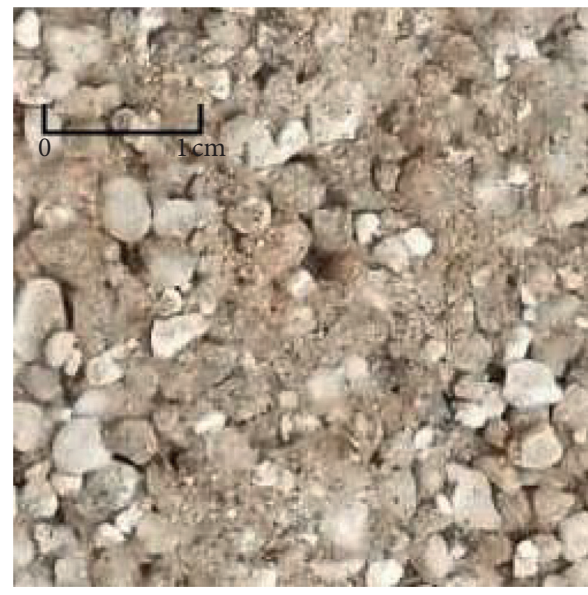

(b)

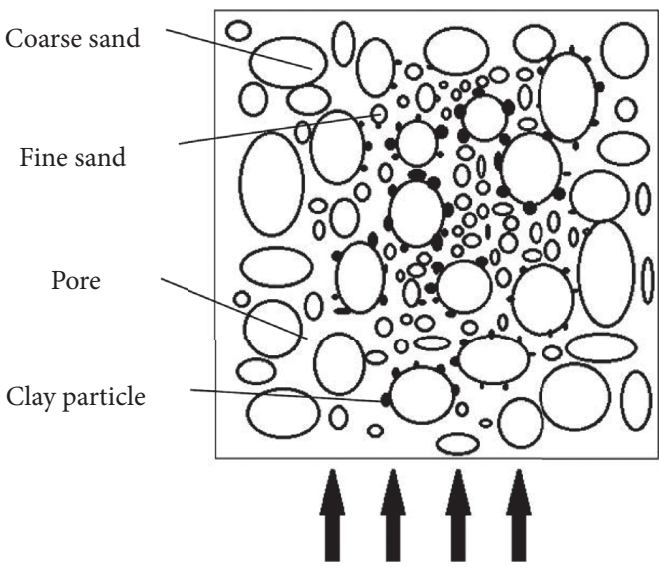

The seepage direction

(a)

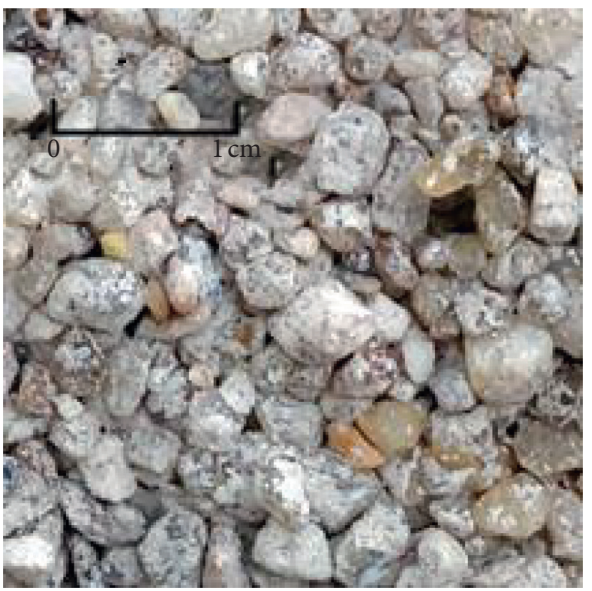

(c)

Figure 6: Comparison between clean gravel and clay-sand-gravel mixture. (a) Schematic diagram of clean gravel and clay-sand-gravel mixture. (b) Image of gravel without clay. (c) Image of gravel with clay.

of three parts: sand grain and gravel grain, clay grain, and pores. The total volume of the solid soil particles is 1 , where the volume of clay particles with content $\mathrm{cc}$ is $f_{c}=\mathrm{cc} \times \alpha$, the volume of sand particles is $1-f_{c}$, and the intergranular porosity ratio $e_{s}$ can be expressed as follows:

$$
e_{s}=\frac{e+f_{c}}{1-f_{c}} .
$$

The intergranular pores of each sample are shown in Table 4; the intergranular porosity ratio of clean gravel is smaller than that of clay-sand-gravel with the same fine particle content. Therefore, the critical hydraulic gradient of
TABLE 4: Intergranular porosity ratio of each sample.

\begin{tabular}{lc}
\hline Sample no. & $e_{s}$ \\
\hline CFC-1 & 0.59 \\
CFC-2 & 0.523 \\
CFC-3 & 0.481 \\
FC-1 & 0.574 \\
FC-2 & 0.5 \\
FC-3 & 0.4515 \\
CS-0 & 0.5 \\
CS-1 & 0.511 \\
CS-2 & 0.523 \\
CS-3 & 0.535 \\
CS-4 & 0.546 \\
\hline
\end{tabular}


each sample in the CFC group was smaller than that of the samples in the FC group with the same fine particle content. Additionally, the critical flow velocity was greater than that of group FC.

In the stable seepage state and particle blockage stage, the fine sand migrated but was not brought out of soils in large quantities, and the sample was not destroyed. When the failure critical hydraulic gradient was reached, the fine sands were removed from the soil, and the destruction of the sample began. Therefore, the numerical size of the failure critical hydraulic gradient can be used as a criterion for assessing whether the clay-sand-gravel mixture is prone to destruction. The test results revealed that the grain size distribution curve can still be used as a criterion to assess whether the clay-sand-gravel mixture is more susceptible to damage, compared with the clean gravel, owing to internal erosion. The grain size distribution curve of the clay-sandgravel mixture samples has a flatter slope in the fine fraction compared with that of the clean gravel sample; thus, the claysand-gravel mixture samples are more likely to be destroyed. Although the clay content of fine particles in the clay-sandgravel mixture was only $10 \%$, the reduction of its critical hydraulic gradient was enormous compared with that of the clean gravel, and even the critical hydraulic gradient of FC-3 approximately doubled compared with that of CFC-3. Hence, it is concluded that clay greatly influences the critical hydraulic gradient of the soil's internal erosion.

4.2. Head Water, Hydraulic Gradient, and Hydraulic Conductivity of CFC and FC Groups. Figure 7 presents the variation of hydraulic conductivity with hydraulic gradient for CFC and FC groups. With the same fine particle content, the hydraulic conductivity of the samples in the CFC group was higher than that of the samples in the FC group. During the stable seepage stage, the hydraulic conductivity of CFC-1 and FC-1 decreased as the hydraulic gradient increased, while that of the other samples remained unchanged. During the particle blockage stage, the hydraulic conductivity of each sample began to decrease. Additionally, with a lower fine particle content, the extent of hydraulic conductivity reduction was greater. With the same fine particle content, the extent of hydraulic conductivity reduction for the CFC group was greater than that of the FC group. At the seepage failure stage, the hydraulic conductivity of the sample began to increase again. A lower clay content made the intergranular pores of the samples in the CFC group larger than those of the samples in the FC group. Additionally, the water-passing capacity of the samples in the CFC group was greater than that of the samples in the FC group. According to the Kozeny-Carman equation, $k \propto e^{3} / 1+e$, the hydraulic conductivity of the samples in the CFC group was greater than that of the samples in the FC group.

As the water head rose, various moving particles blocked pores smaller than their own particle size and prevented other particles from passing through, which caused the fine particles in this area to accumulate, and the blocked fine particles gradually occupied the intergranular pores. With a smaller fine particle content, the intergranular pores became larger. Then, as the pores that could be blocked by fine particles became larger, the decrease of the intergranular porosity ratio in the blocked area became greater, and the decrease of the permeability coefficient was also greater. Likewise, because the intergranular pores of the CFC group were larger than those of the FC group, the reduction of hydraulic conductivity for the CFC group was larger than that for the FC group. With high hydraulic gradients, the fine particles blocked in the pores were washed out of the soil sample, the seepage pipe became unobstructed again, and the sample's hydraulic conductivity suddenly increased.

Variation of hydraulic gradient and hydraulic conductivity with water head for FC and CFC groups is shown in Figure 8 . The hydraulic gradients of the top half, lower half, and total of the sample were calculated according to the water head of three standpipes, respectively. Then, the permeability coefficient of the corresponding part was obtained using Darcy's law: $k=v / i$. Because the sample was made from the bottom up, the lower half of the sample was denser than the top half. Therefore, as revealed by the hydraulic gradient test results, the hydraulic conductivity of the lower half was larger than that of the top half, while the hydraulic conductivity was larger in the lower half and smaller in the top half. Under the same water head, the top half, lower half, and total hydraulic gradients of the claysand-gravel mixture samples were smaller than those of the clean gravel, and the hydraulic conductivity of the clay-sandgravel mixture was larger than that of clean gravel, because the clay-sand-gravel mixture had larger intergranular void ratio, stronger water-passing capacity, and smaller hydraulic gradient. With the same fine particle content, the external water head of the clay-sand-gravel mixture was smaller than that of clean gravel in the event of blockage and failure.

However, in Figures 8(a) and 8(b), the hydraulic gradient variation of the CFC-1 and FC-1 curves is slightly different from that of the other curves; with the increase of water head, the hydraulic gradient of CFC-1 and FC-1 does not decrease at high water head. The reason for this is that when the fine particle content was low (CFC-1 and FC-1), the pore space of the specimen was large, and the resistance of fine particles when they migrated from the lower half of the specimen to the top half of the specimen was small. This made it easier for the fine particles to block the sample's pores and also made it easier for the hydraulic gradient of the sample to increase with the water head. When the other samples were damaged, most of the fine particles were removed from the soil; thus, the hydraulic gradient decreased with high water head. According to the formula $k=v / i$, the variation of hydraulic conductivity with the water head is opposite to the hydraulic gradient.

4.3. Fine Particle Loss for CFC and FC Groups. After failure, the loss of fine particles has an important influence on the soil strength. The percentage of particle loss, that is, the ratio of particle loss mass to the original particle mass, can better reflect the loss degree of fine particles, and this can be used to investigate the effect of clay on fine particle loss. At the end of the test, the upper, middle, and bottom three groups were 


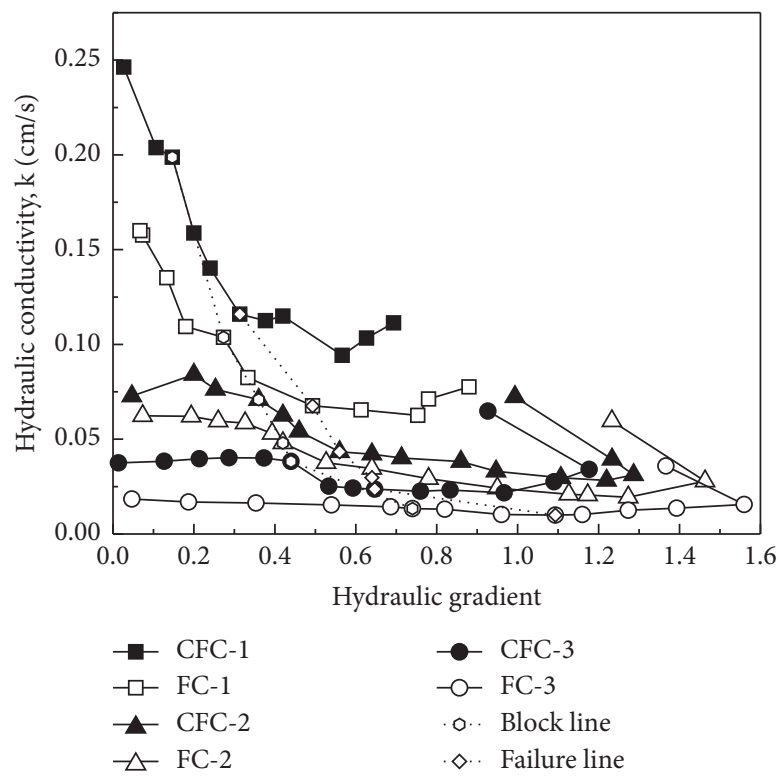

Figure 7: Variation of hydraulic conductivity with hydraulic gradient for CFC and FC groups.

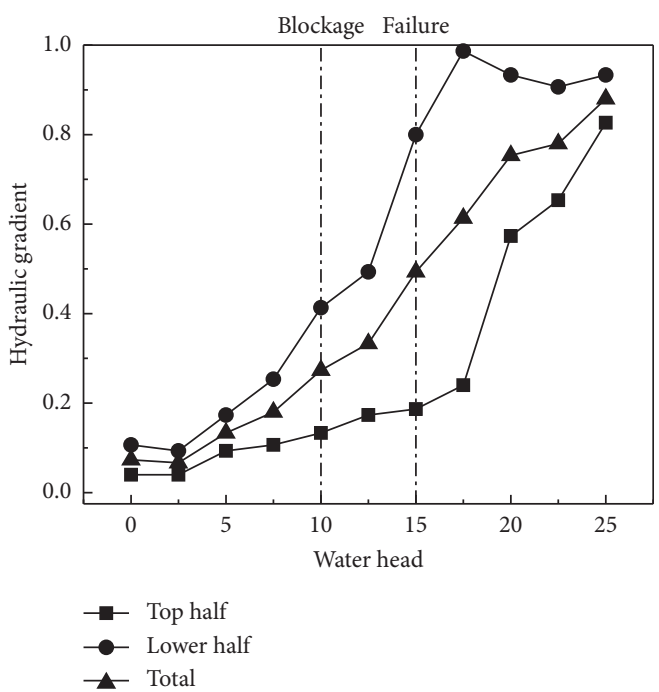

(a)

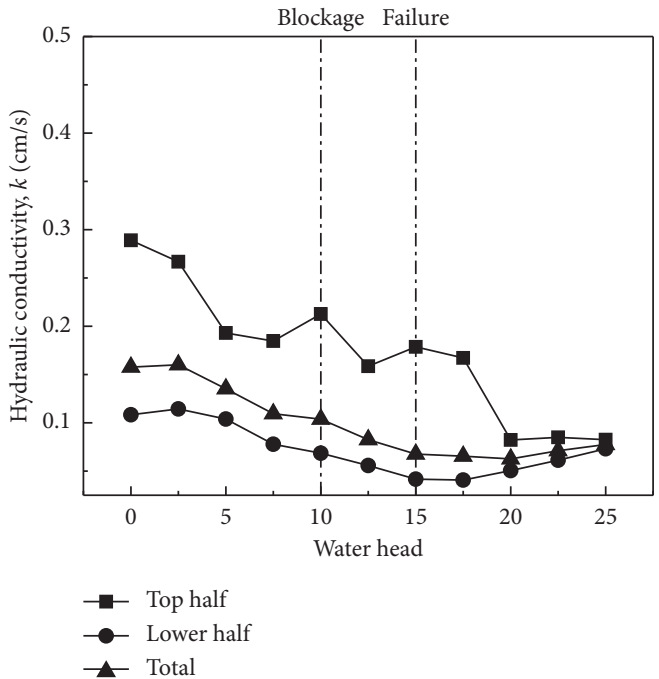

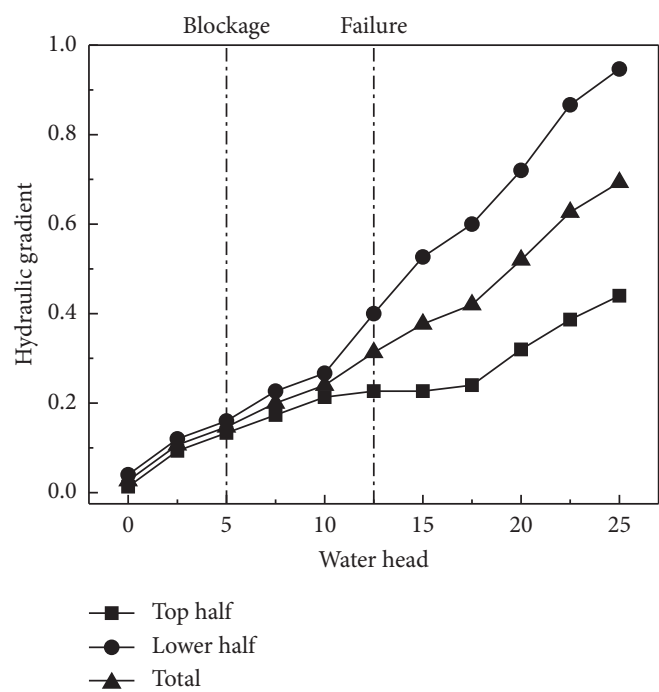

(b)

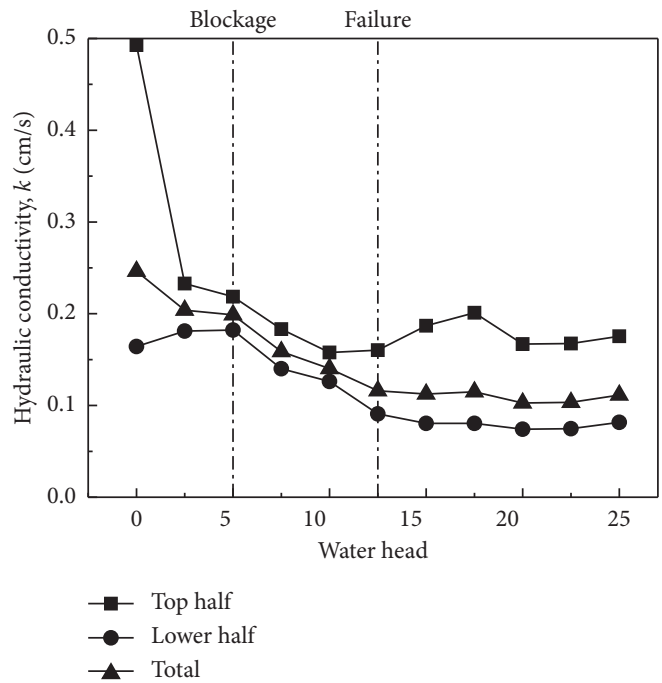

(d)

Figure 8: Continued. 


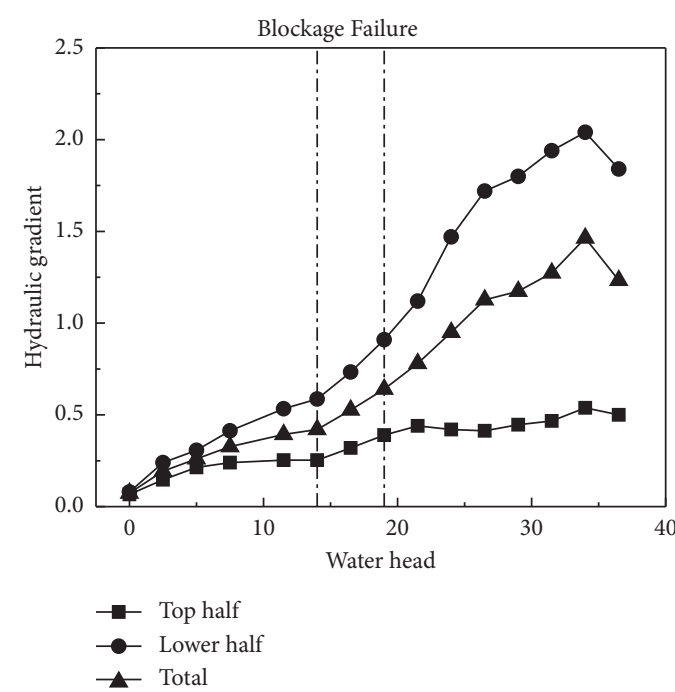

(e)

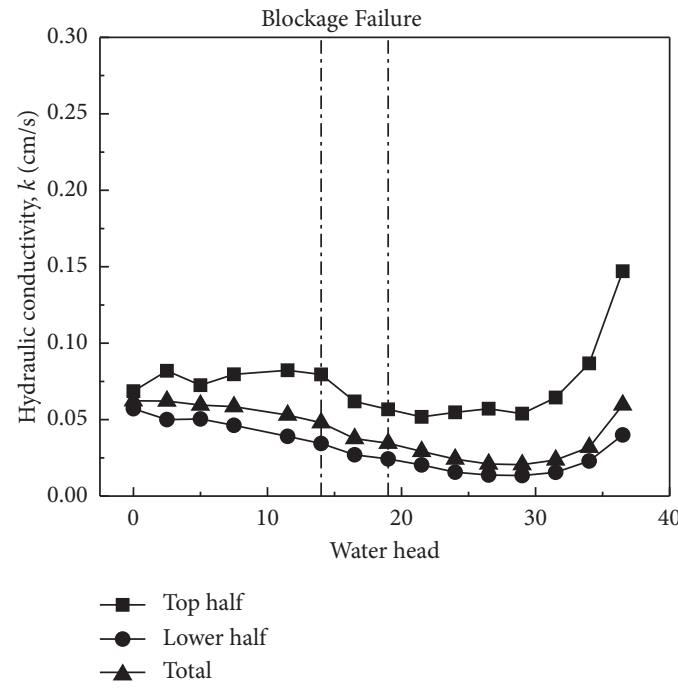

(g)

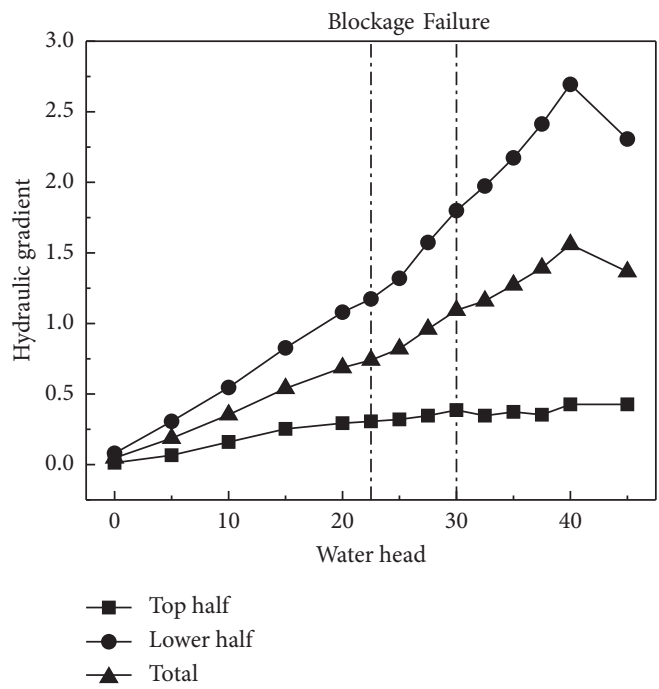

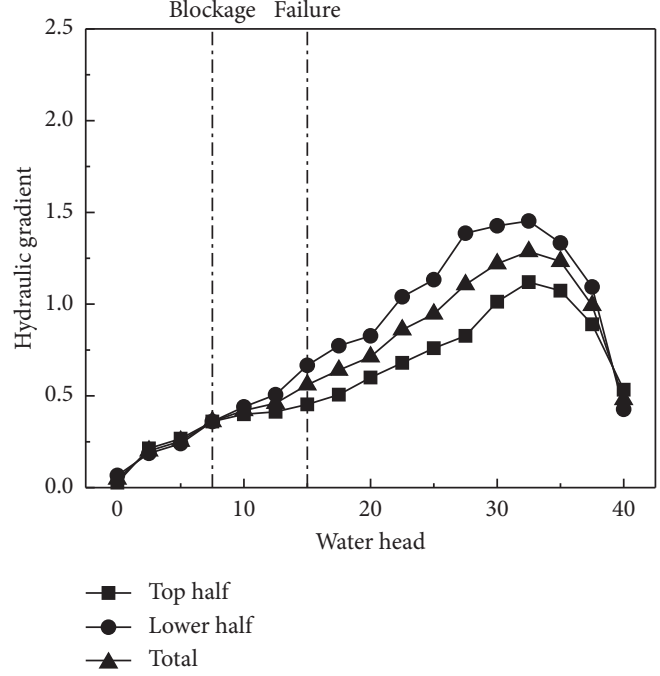

(f)

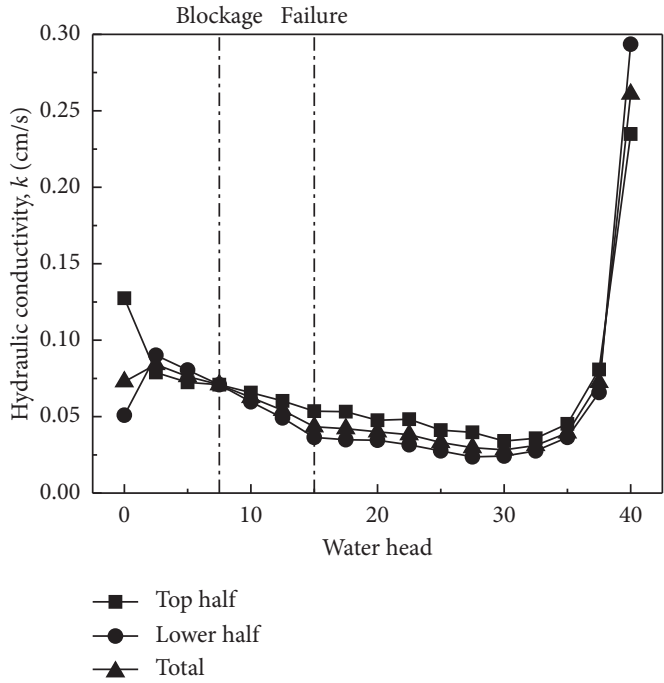

(h)

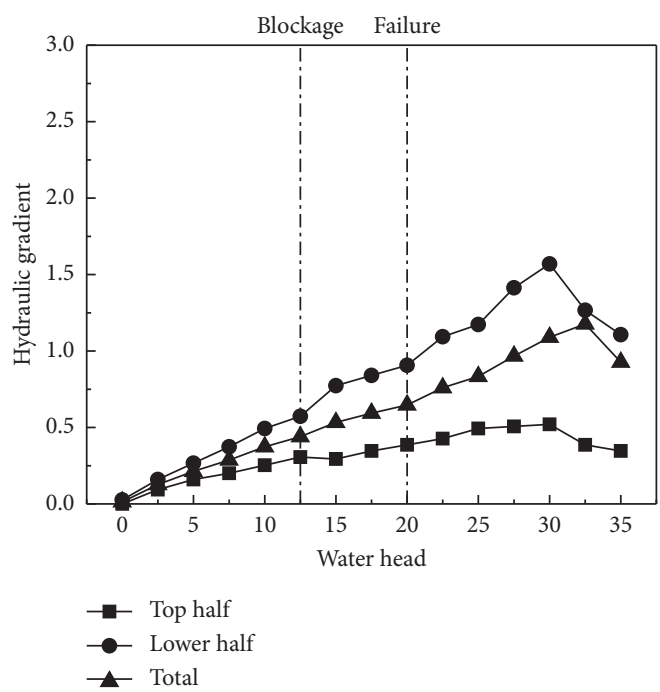

(j)

Figure 8: Continued. 


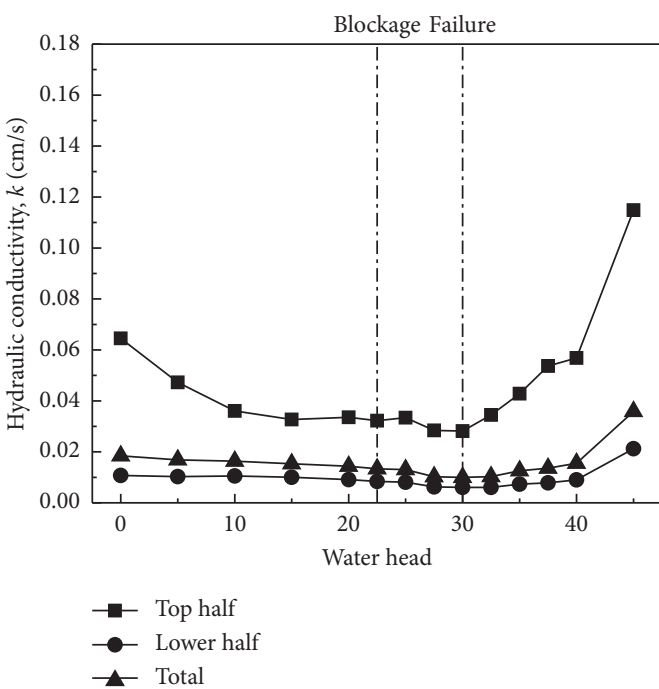

(k)

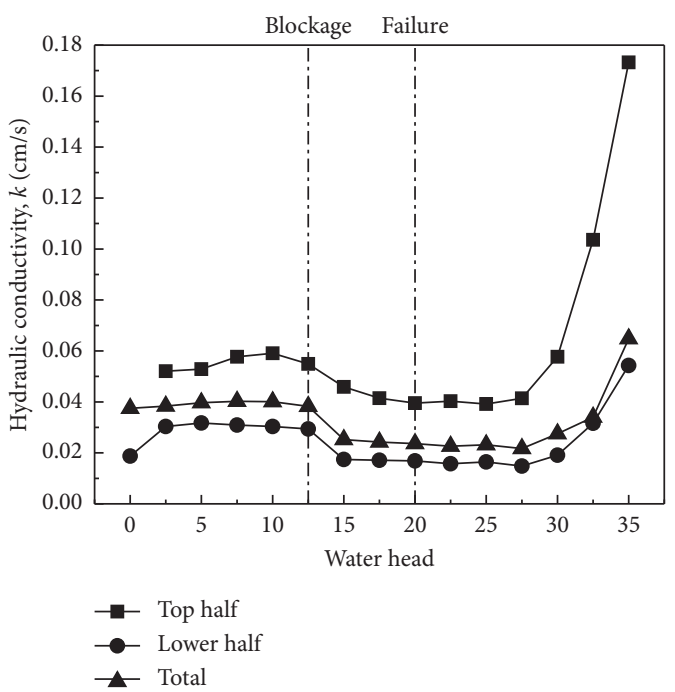

(l)

FIgURE 8: Variation of hydraulic gradient and hydraulic conductivity with water head for FC and CFC groups. (a) Variation of hydraulic gradient of FC-1 with water head. (b) Variation of hydraulic gradient of CFC-1 with water head. (c) Variation of hydraulic conductivity of FC-1 with water head. (d) Variation of hydraulic conductivity of CFC-1 with water head. (e) Variation of hydraulic gradient of FC-2 with water head. (f) Variation of hydraulic gradient of CFC-2 with water head. (g) Variation of hydraulic conductivity of FC-2 with water head. (h) Variation of hydraulic conductivity of CFC-2 with water head. (i) Variation of hydraulic gradient of FC-3 with water head. (j) Variation of hydraulic gradient of CFC-3 with water head. (k) Variation of hydraulic conductivity of FC-3 with water head. (l) Variation of hydraulic conductivity of CFC-3 with water head.

sequentially taken out and dried to obtain the dry mass of each layer; then, the clay of each layer was washed out and each layer without clay was dried to obtain the dry mass of this layer without clay after test. The formula for calculating the loss of fine sand and clay is expressed as follows:

The mass of fine particle loss for this layer: $m_{3}=m_{1}-m_{2}$

The mass of clay loss for this layer: $m_{5}=\left(m_{c} / 3\right)-m_{2}+m_{4}$

The mass of fine sand loss for this layer: $m_{6}=m_{3}-m_{5}$

$m_{1}$ : original mass of this layer

$m_{2}$ : dry mass of this layer after test

$m_{4}$ : dry mass of this layer without clay after test

By comparing the loss of each sample layer, it can be seen that the loss for the samples in the CFC group with the same fine particle content was slightly less than that for the samples in the FC group (shown in Figure 9). The percentage of fine sand loss of CFC-1, CFC-2, and CFC-3 is $3.51 \%$, $11.73 \%$, and $8.95 \%$, respectively, which is less than that of FC-1, FC-2, and FC-3 (5.96\%, 13.73\%, and 9.90\%). The loss of fine sand in the bottom layer of each sample was the largest, while the loss in the upper layer of each sample was the smallest. The fine sand loss of bottom layer of FC-2 is the largest of the three layers of each sample, which is $18.63 \%$. Additionally, even the fine sand mass of the upper layer of CFC-1 and FC-1 increased after internal erosion, also corresponding to the previous analysis in Figures 8(a) and 8(b). Under the action of the seepage force, the fine particles migrated upward, but the coarse particles did not move owing to the large contact force amongst the coarse particles. Therefore, the fine particles gradually migrated and gathered to the upper layer, and either the mass of the fine sand in the upper layer increased or the loss of the fine sand in the upper layer was small.

The internal erosion indicated by the loss of fine particles changed the void ratio, which resulted in the decrease of soil strength from its initial value. Notably, a greater loss of fine particles would lead to further strength reduction [18]. However, when the clay content of the sample is small, the clay grains are fully confined within the void spaces between the coarser grains with no contribution whatsoever in supporting the coarser grain skeleton. Clay grains are inactive in the transfer of interparticle forces. The mechanical behavior is affected primarily by the coarser grain contacts. During deformation, the clay grains may move from one pore space to another without significantly contributing to the mechanical response of the soil, so the loss of fine sand would lead to the soil's strength reduction. As shown in Figure 9, a clay content of $10 \%$ reduced the loss of fine sand in each layer of CFC group samples with the same fine particle content, compared with the FC group samples, but did not alter the change trend of fine sand loss in space. The loss of fine sand in the FC and CFC groups decreased along the seepage direction. Therefore, regardless of whether it was a clay-sand-gravel mixture or clean gravel, the degree of reduction in the soil strength after failure increased from downstream to upstream. Hence, it should be kept in mind that the upstream soil may be destroyed first in an 


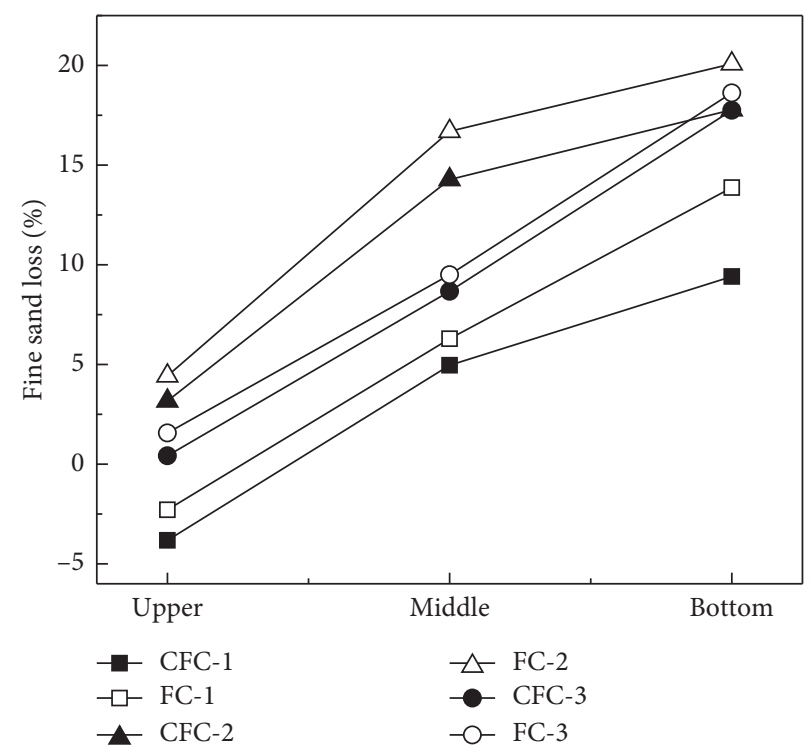

Figure 9: Percentage of fine sand loss for CFC and FC groups.

engineering project. Additionally, compared with clean sand, the clay-sand-gravel mixture was more prone to failure, but the strength reduction after failure was smaller than that of clean gravel.

As can be seen in Figure 10(a), the clay loss also gradually decreased from the bottom layer to the upper layer of the sample, and the clay content even increased in the upper layer of CFC-3. Figure 10(b) shows the variation between clay loss and fine sand loss of each sample in the CFC group. For each sample in the CFC group, there existed a positive correlation between the clay loss and fine sand loss, and the percentage of clay loss was larger than the loss percentage of fine sand. The clay moved upward from the bottom under the action of the seepage force, and owing to the small particle size it migrated not only in the pipeline formed by the gravel, but also in the pipeline formed by the fine sand. Therefore, the clay migration could not be easily blocked and the percentage of clay loss was large.

\subsection{Critical Hydraulic Gradient and Critical Velocity of the CS} Group. CS samples are clay-sand-gravel mixtures with fixed fines content, but increasing clay percentages. During the test, the indoor temperature was $10^{\circ} \mathrm{C}$ and the dynamic viscosity coefficient of water $\eta=1.306 \times 10^{-6} \mathrm{~m}^{2} / \mathrm{s}$. According to the calculation formula $R_{e}=v d_{10} / \eta$, each sample had a Reynolds number $<5$ as shown in Table 5; therefore, it is considered that the water flow still complied with Darcy's law.

Figure 11 shows the variation of flow velocity with hydraulic gradient for CS group. During the stable seepage stage, the critical hydraulic gradient of the blockage decreased as the clay content increased, and the critical velocity of the blockage increased with the clay content. During the particle blockage stage, the increase of the flow rate slowed down with the increase of the hydraulic gradient, and samples CS-0, CS-1, and CS-2 even exhibited a decrease in flow velocity. During the seepage failure stage, the critical hydraulic gradient of each sample in the CS group generally decreased as the clay content increased, and the critical flow velocity for failure increased with the clay content.

Samples with larger clay content had larger intergranular pores, and the filtering effect on fine sand migration within the soil became weaker. Therefore, the hydraulic gradient required by the soil sample to overcome blockage decreased as the clay content increased, and the critical flow velocity increased with the clay content (as presented in Table 6). Although the critical hydraulic gradient of CS-1 and CS-4 increased in varying degrees compared with other samples, which may be caused by the random distribution of particles in the samples, the failure critical hydraulic gradient of each sample generally decreased with the increase of clay content. With the increase of clay content of clay-sand-gravel mixture from 0 to $25 \%$, the critical hydraulic gradient of the claysand-gravel mixture decreased from 0.64 to 0.386 , which made it more prone to failure. Similarly, the grain size distribution curve can still be used as a criterion to determine whether the soil is susceptible to failure owing to internal erosion. Notably, samples with higher clay content and flatter slope in the fine portion of the grain size distribution curve were more susceptible to damage.

4.5. Head Water, Hydraulic Gradient, and Hydraulic Conductivity of the CS Group. With the same hydraulic gradient, the hydraulic conductivity of each sample in the CS group increased with the clay content (as shown in Figure 12). At the stable seepage stage, the hydraulic conductivity of each sample remained essentially unchanged. At the particle blockage stage, the permeability coefficient began to decrease; as the clay content increased, the extent of the permeability coefficient reduction became greater. At the seepage failure stage, the hydraulic conductivity gradually started to rise. As the clay content increased, the intergranular porosity and the cross section water-carrying area of the sample increased, and the corresponding hydraulic 


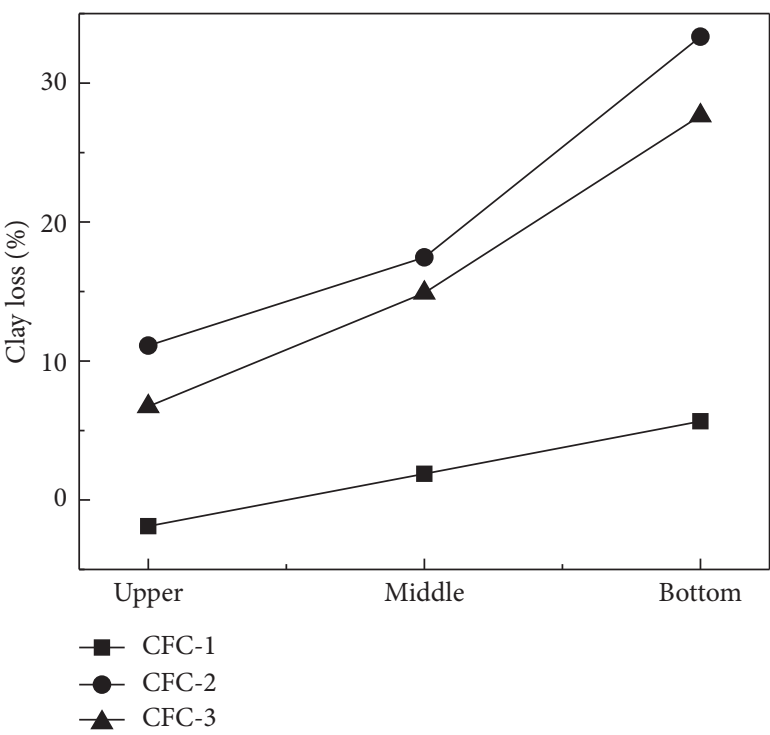

(a)

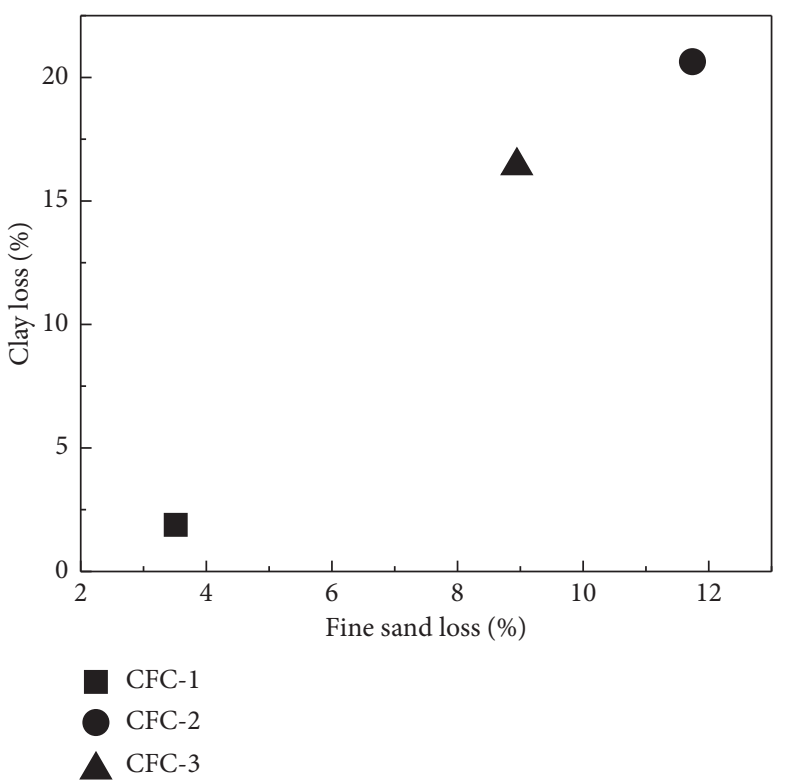

(b)

FIgure 10: Clay loss percentage for CFC and FC groups. (a) Percentage of clay loss. (b) Clay loss variation with fine sand loss.

TABLE 5: Reynolds number of the CS group.

\begin{tabular}{llllllr}
\hline & CS-0 & CS-1 & CS-2 & CS-3 & CS-4 & CS-5 \\
\hline$v(\mathrm{~cm} / \mathrm{s})$ & 0.074 & 0.086 & 0.072 & 0.078 & 0.080 & 0.089 \\
$d_{10}(\mathrm{~mm})$ & 0.192 & 0.192 & 0.192 & 0.192 & 0.192 & 0.192 \\
$R_{e}$ & 0.108 & 0.126 & 0.106 & 0.115 & 0.118 & 0.131 \\
\hline
\end{tabular}

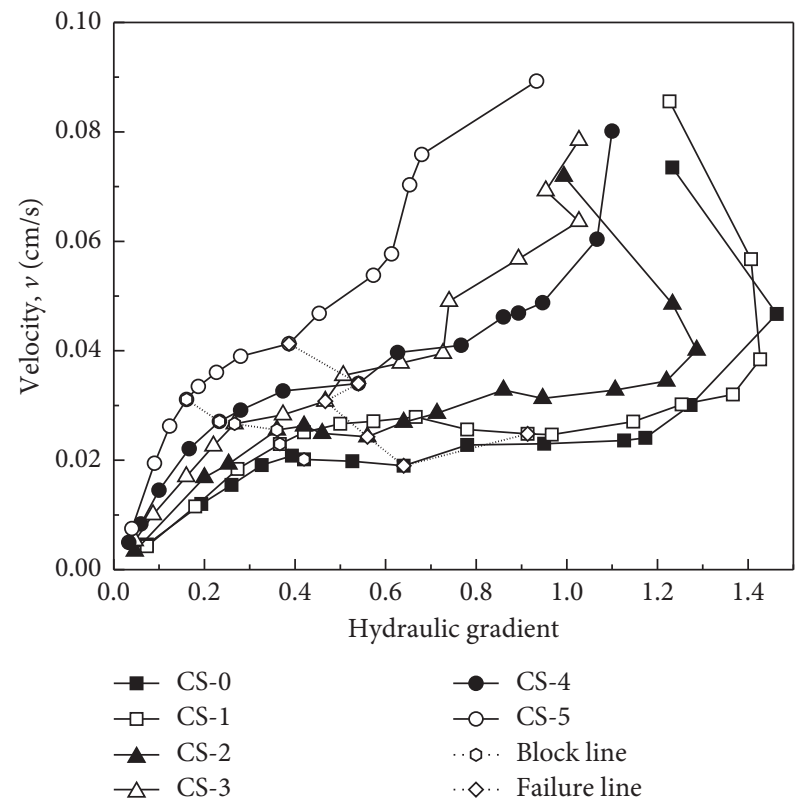

FIGURE 11: Variation of flow velocity with hydraulic gradient for the CS group.

conductivity also increased. As the hydraulic gradient increased, the moving particles started becoming blocked and gradually occupied the intergranular pores. As the clay content increased, the intergranular pores became larger, these larger pores could be blocked by fine particles, and the intergranular porosity and hydraulic conductivity reduction in the blocked area became larger. With a high hydraulic gradient, the particles blocked by the sample pores were flushed out of the pores, and the hydraulic conductivity of the samples increased again.

For the same reasons as for the preparation of the samples in the CFC and FC groups, the test results for the hydraulic gradient of each sample in the CS group revealed that the hydraulic conductivity of the lower half was greater than that of the top half. Additionally, the hydraulic conductivity was larger in the lower half and smaller in the top half. As can be seen in Figure 13, with the same water head, as the clay content in the sample increased, the hydraulic gradient of the upper and lower part of the sample became smaller, and the hydraulic conductivity was opposite of the hydraulic gradient. As the clay content increased, the required water head became increasingly smaller when the sample was blocked and damaged.

Samples CS-3, CS-4, and CS-5 were different from other samples in that their hydraulic gradient increased with the external head. Because some fine sand was replaced by clay, the intergranular pore became larger. As the water head increased, the migrated fine sand gradually occupied the intergranular pores, the intergranular pores of the sample became smaller, and the mechanical energy was dissipated 
TABLE 6: Critical hydraulic gradient and critical flow velocity for the CS group.

\begin{tabular}{|c|c|c|c|c|c|c|}
\hline & CS-0 & CS-1 & CS-2 & CS-3 & $\mathrm{CS}-4$ & CS-5 \\
\hline Blockage critical hydraulic gradient & 0.42 & 0.37 & 0.36 & 0.267 & 0.233 & 0.161 \\
\hline Blockage critical velocity $(\mathrm{cm} / \mathrm{s})$ & 0.0202 & 0.0229 & 0.0251 & 0.0267 & 0.0271 & 0.0311 \\
\hline Failure critical hydraulic gradient & 0.64 & 0.913 & 0.56 & 0.47 & 0.54 & 0.386 \\
\hline Failure critical velocity $(\mathrm{cm} / \mathrm{s})$ & 0.0194 & 0.0248 & 0.0243 & 0.0308 & 0.034 & 0.0413 \\
\hline
\end{tabular}

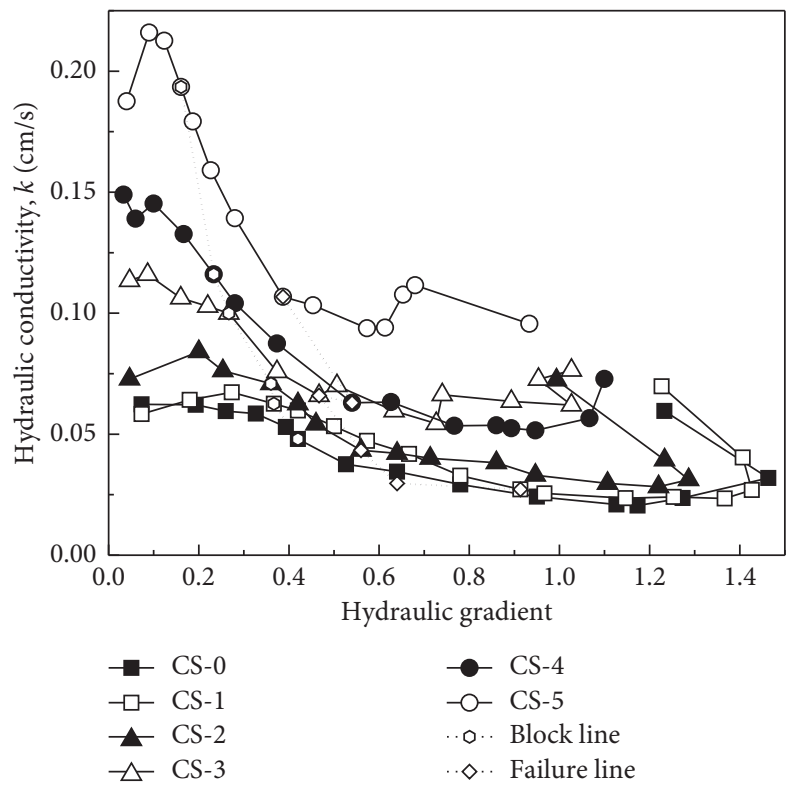

FIGURE 12: Variation of hydraulic conductivity with hydraulic gradient of CS samples.

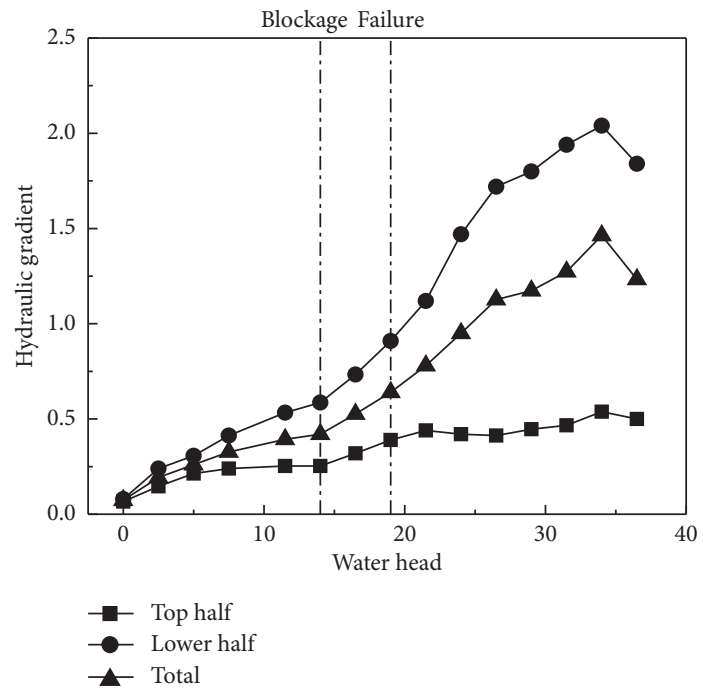

(a)

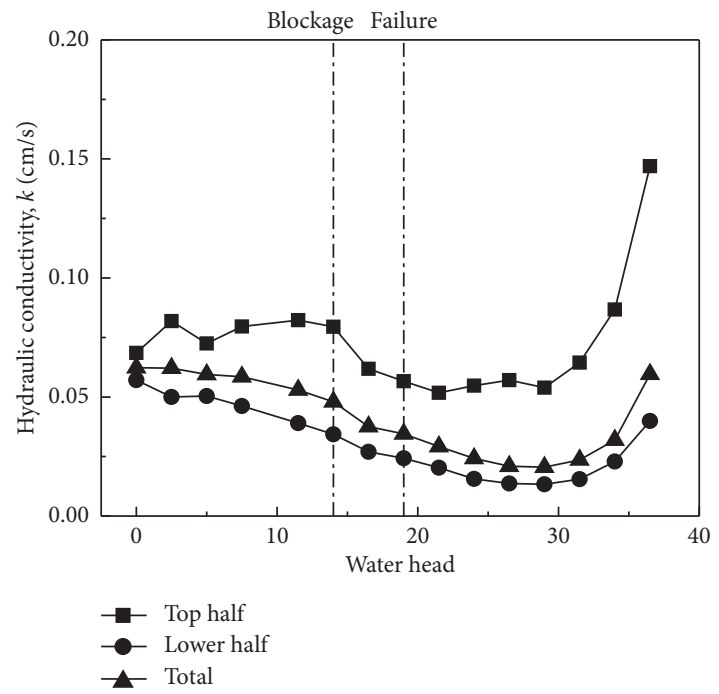

(b)

FIgURE 13: Continued. 


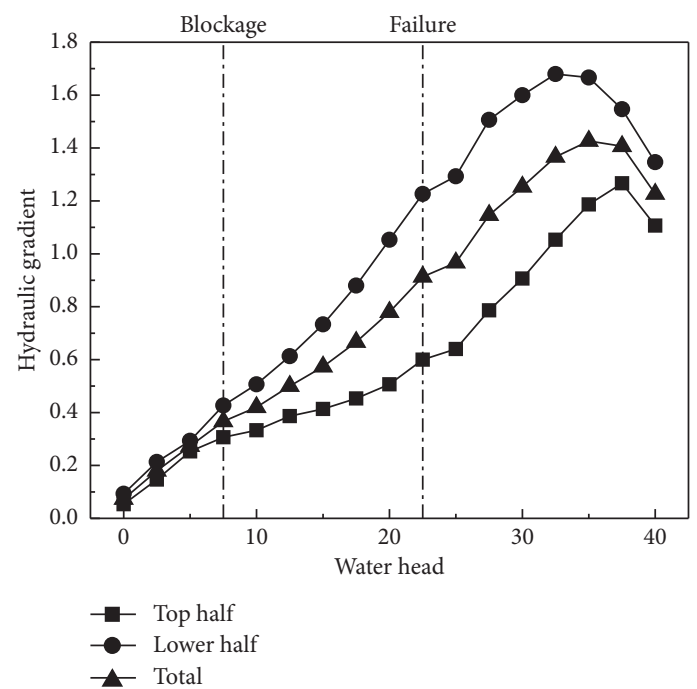

(c)

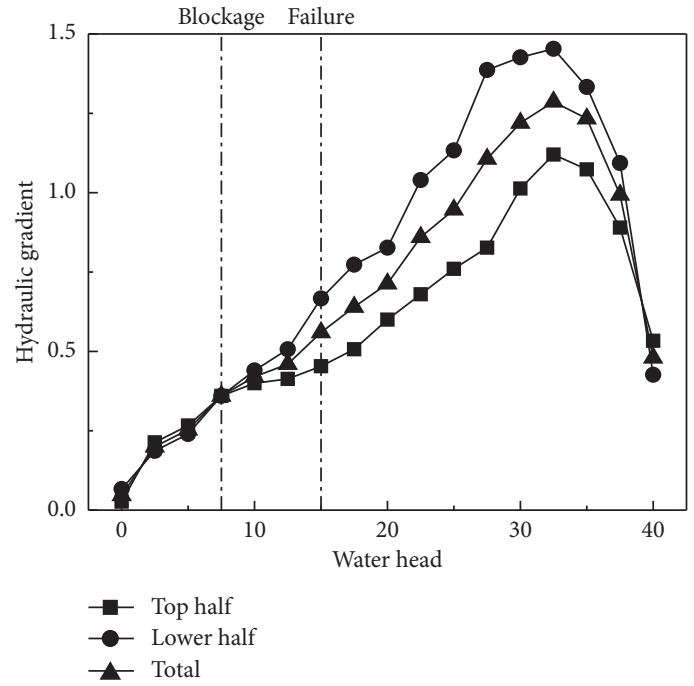

(e)

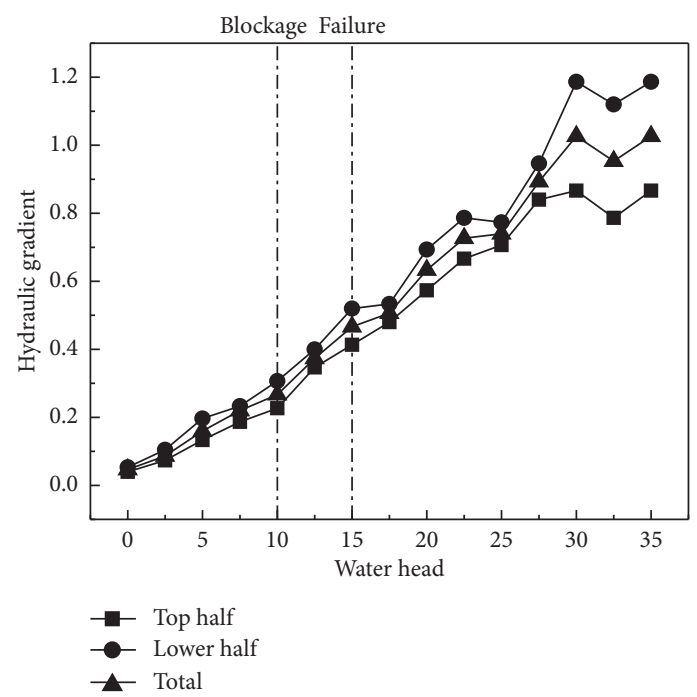

(g)

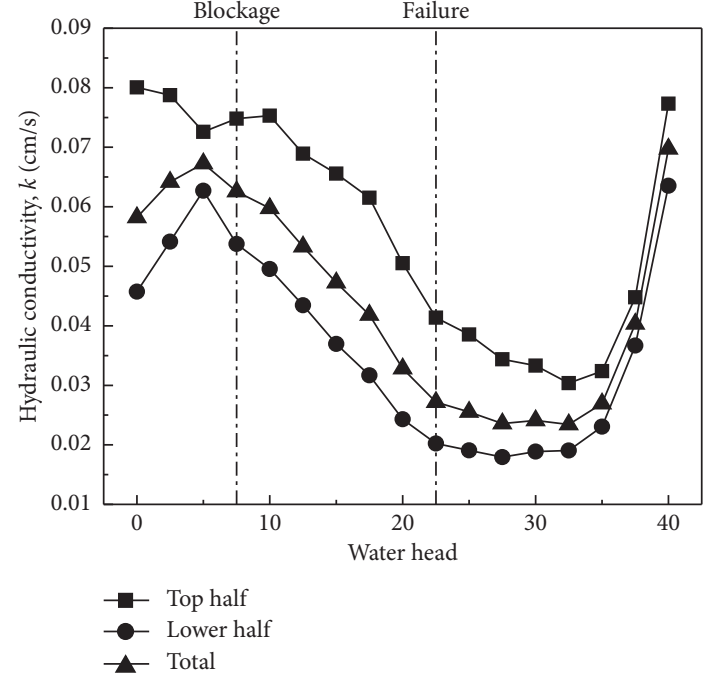

(d)

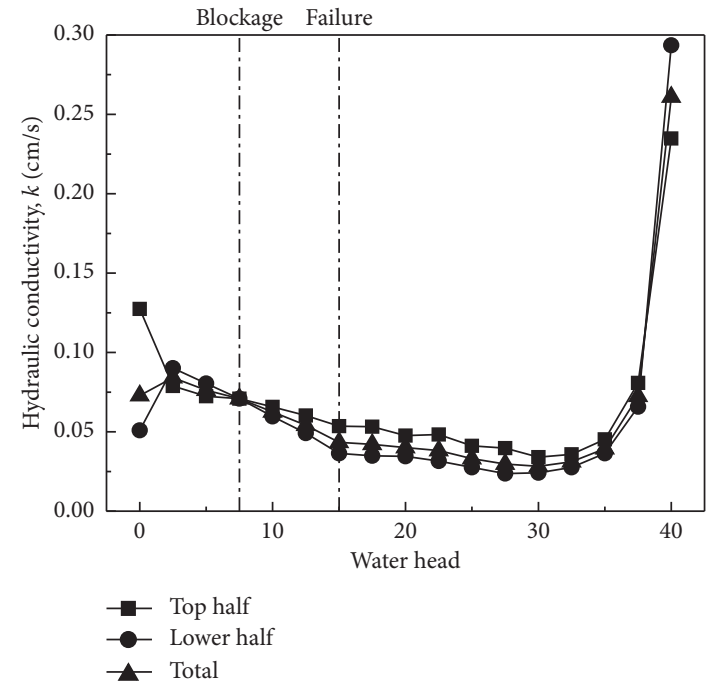

(f)

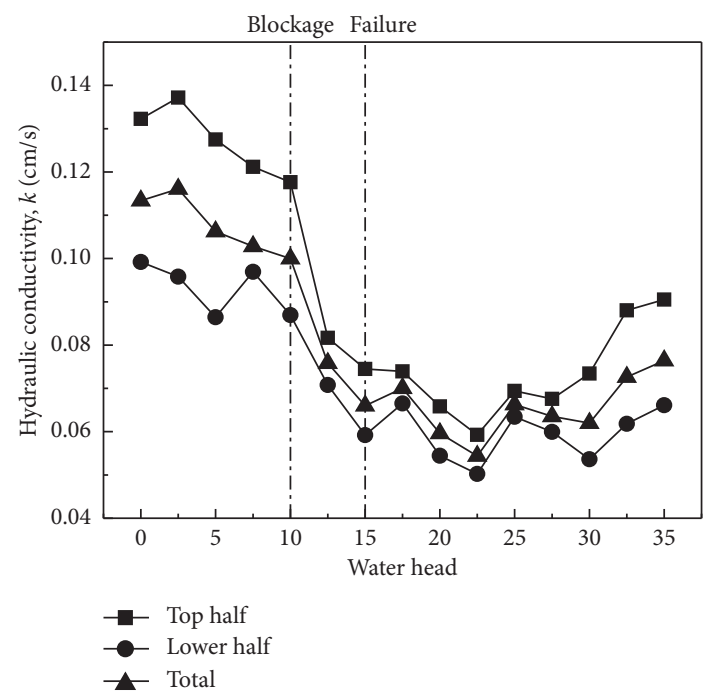

(h)

Figure 13: Continued. 


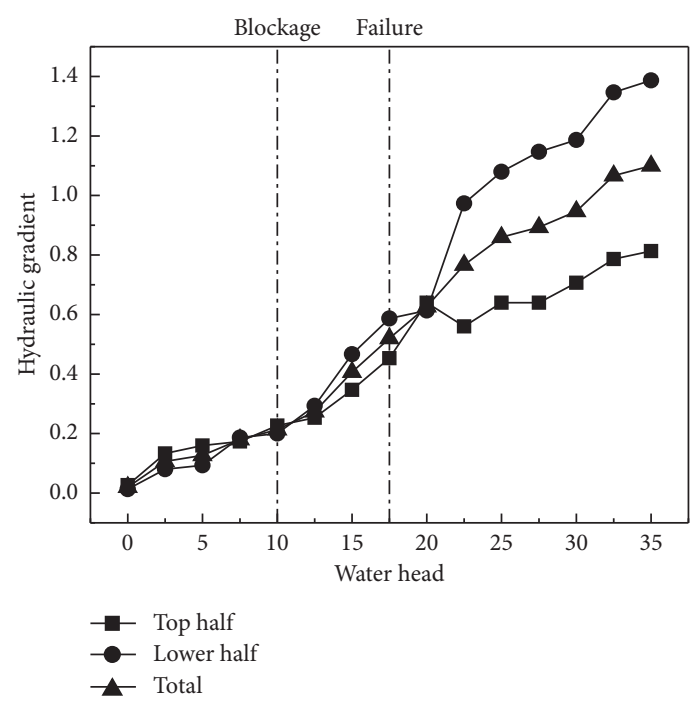

(i)

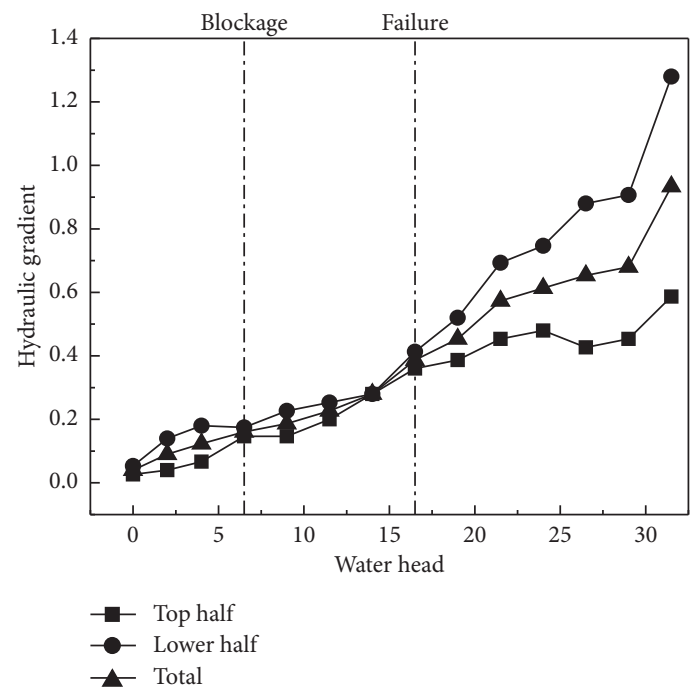

$(\mathrm{k})$

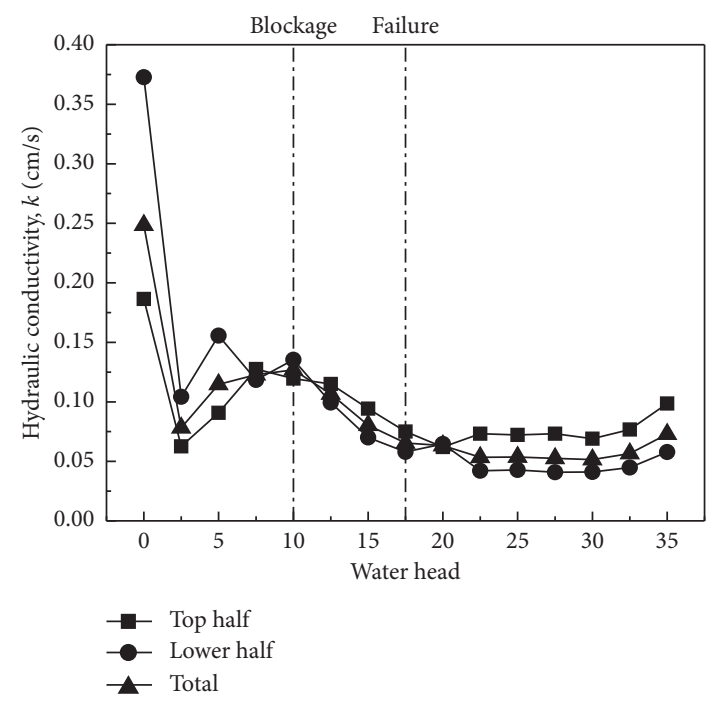

(j)

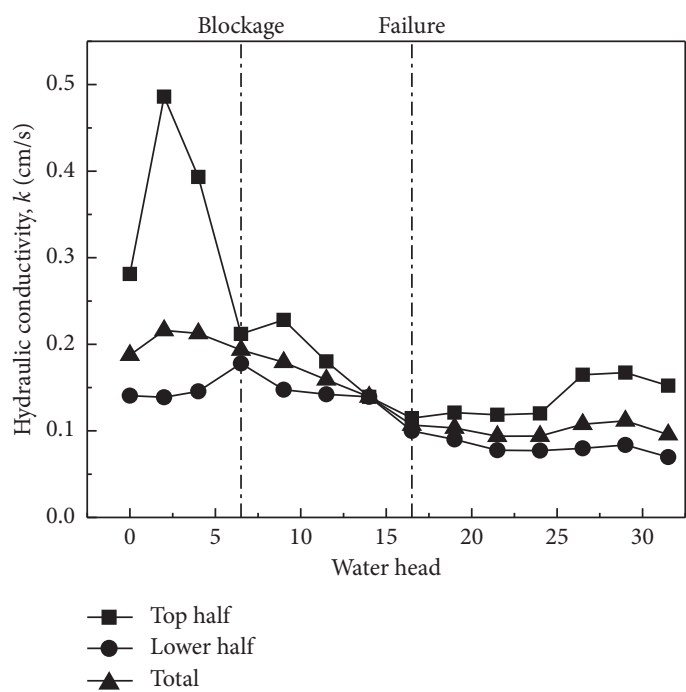

(l)

FIGURE 13: Variation of hydraulic gradient and hydraulic conductivity with water head for the CS group. (a) Variation of hydraulic gradient with water head for CS-0. (b) Variation of hydraulic conductivity with water head for CS-0. (c) Variation of hydraulic gradient with water head for CS-1. (d) Variation of hydraulic conductivity with water head for CS-1. (e) Variation of hydraulic gradient with water head for CS2. (f) Variation of hydraulic conductivity with water head for CS-2. (g) Variation of hydraulic gradient with water head for CS-3. (h) Variation of hydraulic conductivity with water head for CS-3. (i) Variation of hydraulic gradient with water head for CS-4. (j) Variation of hydraulic conductivity with water head for CS-4. (k) Variation of hydraulic gradient with water head for CS-5. (l) Variation of hydraulic conductivity with water head for CS-5.

by the water flow through the same length of the penetration path to overcome the increasing friction resistance. Hence, the hydraulic gradient gradually increased.

4.6. Fine Particle Loss for the CS Group. Figure 14 shows the percentage of fine sand loss for CS group. Amongst the losses of the three layers, the fine sand loss in the bottom layers of each sample was the largest. In the bottom layer of each claysand-gravel mixture sample, the loss of fine sand gradually increased as the clay content decreased. In the bottom layer of the CS-0 sample, the loss percentage of the fine sand was
$20.77 \%$, while that in the bottom layer of the CS-5 sample was only $8.75 \%$. The fine sand loss value in the middle layer was between the values of the bottom layer and the upper layer, and the loss of fine sand in the middle layer of each sample also conformed to the rule whereby the loss decreases as the clay content increases. As the clay content increased, the upper layer loss of each sample became increasingly smaller. The loss of fine sand in the upper layer of each sample did not exceed 5\%. The fine sand loss in the CS-0, CS1 , and CS-2 samples was similar, and all losses were net losses. As the samples underwent internal erosion over a long period of time under high hydraulic gradients, the fine 


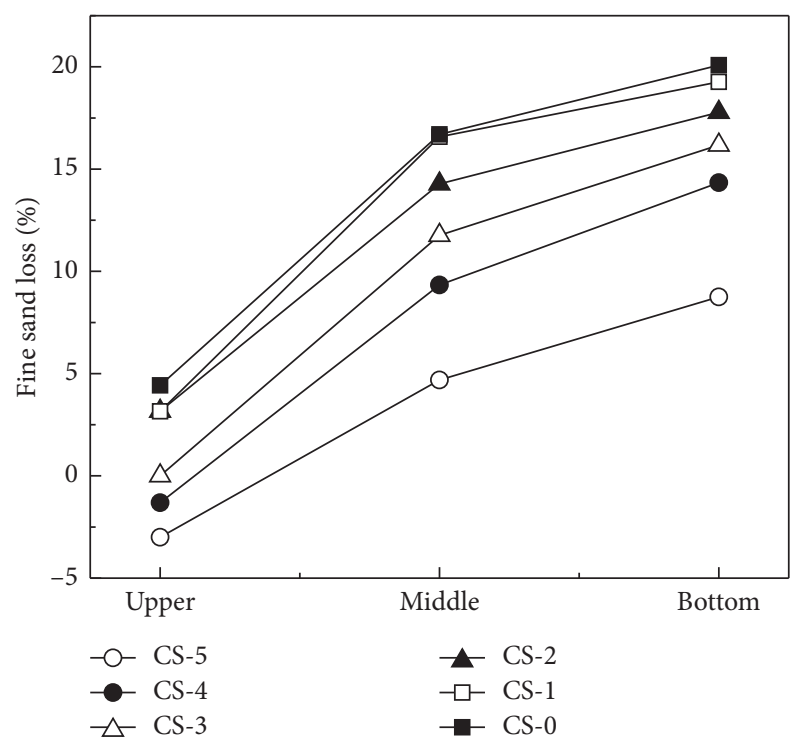

FIgURE 14: Percentage of fine sand loss for the CS group.

particles deposited in the upper layer were transferred out in large quantities. The loss percentage of fine sand in the upper layer of sample CS-3 was $0 \%$, and the amount of fine sand flowing into the upper layer was equal to the amount of fine sand flowing out. The loss percentage of fine sand in samples CS- 5 and CS- 4 was $-3 \%$ and $-1.33 \%$. After the test, the fine sand mass in the upper layer of samples CS-4 and CS-5 increased, and the number of fine sand particles flowing into the upper layer was larger than the number of fine sand particles flowing out, which also accords with the hydraulic gradient and hydraulic conductivity change with the water head, as shown in Figure 13.

As can be seen in Figure 14, the loss of fine sand in each layer decreased as the clay content increased, but this did not change the spatial distribution trend of the fine sand loss, which decreased along the seepage direction. Therefore, as the clay content increased, the extent of soil strength reduction for each layer decreased after the failure, but increased from downstream to upstream. As shown in Figure 15(a), the percentage of clay loss gradually decreased from the bottom layer to the upper layer of each sample. The clay loss percentage in the bottom layer of sample CS- 1 was $45 \%$, and that in the upper layer of sample CS-5 was $-3 \%$, which means that the clay content increased after the erosion damage. From the viewpoint of loss per layer, the clay loss percentage in each layer decreased as the clay content increased. From the viewpoint of total clay loss for each sample, as the clay content in the sample increased, the clay loss decreased. Additionally, the clay loss percentage in CS group is greater than that of fine sand from Figure 15(b) with the same reason of FC group and CFC group.

4.7. Limitation and Further Study. The proportion of clay mass to total mass of each sample is limited to less than $5 \%$, which is one of the defects of this paper, and the effect of higher clay content on internal erosion will be studied later. Although the change range of clay content is small, the effect

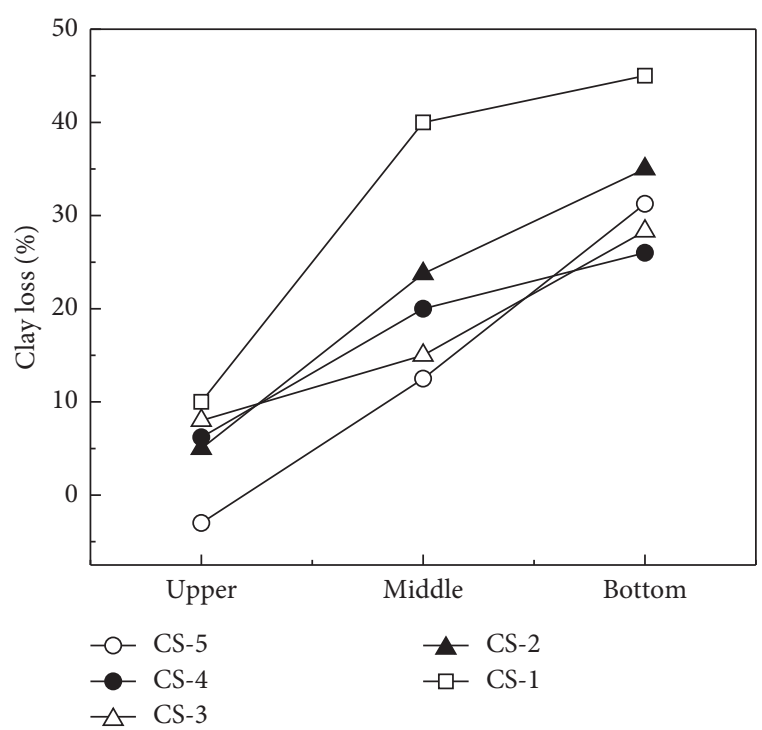

(a)

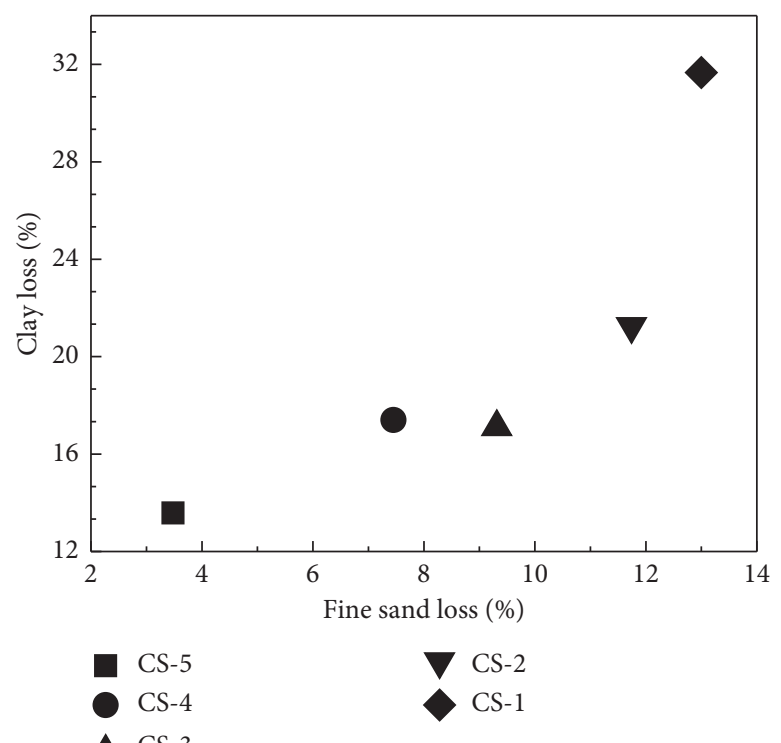

(b)

FIgURe 15: Percentage of clay loss for CS group. (a) Percentage of clay loss. (b) Clay loss variation with fine sand loss.

of clay on internal erosion of clay-sand-gravel mixture is huge, which is reflected in critical hydraulic gradient and fine sand loss. For example, the blockage critical hydraulic gradient and failure critical hydraulic gradient of CFC-3 are far less than FC-3, and the loss of fine sand of FC-3 is also greater than CFC-3. Through the experiment results and analysis, the reason for this is that the existence of clay enlarges the pipelines pores of sand migration. In addition, according to the theory proposed by Heng and Qiu [33], when the percentage of clay mass to total mass is less than $9 \%$, the lubrication of the clay between the coarser particles can "help" change the relative position of the coarser particles. As presented in Figure 16, it is not possible to determine whether the intergranular void ratio or the lubrication of clay particles makes the migration of fine sand 


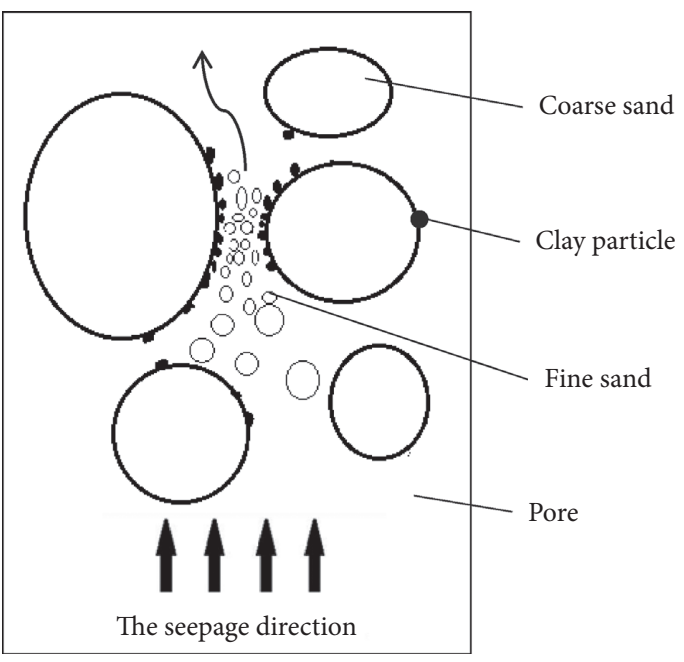

FIGURE 16: Schematic diagram of the migration of fine sand of claysand-gravel mixture.

easier in this test, and the influence of the cohesion of clay on fine sand transport was not studied either. A new experiment needs to be designed to investigate the effect of lubrication of clay on fine sand migration during internal erosion. However, whether there is "lubrication" of clay particles on the migration of fine sand between particles needs further study.

\section{Conclusions}

In this study, internal erosion tests were conducted for claysand-gravel mixture samples, clean gravel samples with different fine particle content, and clay-sand-gravel samples with different clay content. Although the clay content in the fine particles only varied from $0 \%$ to $25 \%$, and the change range of the clay mass in the total sample mass was smaller, the effect of the clay on the samples' critical hydraulic gradient, critical flow velocity, and particle loss was enormous. The following conclusions were drawn from this study:

(1) The clay-sand-gravel mixture and clean sand both underwent the same seepage stage. However, the critical hydraulic gradient of the clay-sand-gravel mixture was higher than that of clean gravel with the same fine particle content, and the critical velocity was lower than that of clean gravel with the same fine particle content. For the clay-sand-gravel mixture samples with different clay content, as the clay content increased, the critical hydraulic gradient decreased and the critical flow velocity increased.

(2) With the same water head, the hydraulic conductivity of the clay-sand-gravel mixture was higher than that of clean gravel and increased with the clay content; with the same water head, the hydraulic gradient of the clay-sand-gravel mixture was smaller than that of clean gravel and decreased with the clay content.

(3) The clay-sand-gravel mixture and clean gravel exhibited the same fine particle spatial loss characteristics: the fine sand loss percentage decreased along the seepage direction. However, the fine sand loss of the clay-sand-gravel mixture was lower than that of clean gravel with the same fine particle content; for the clay-sand-gravel mixture samples with different clay content, as the clay content increased, the fine sand loss and clay loss decreased. Additionally, the percentage of clay loss of each sample is greater than that of fine sand.

\section{Data Availability}

The data used to support the findings of this study are available from the corresponding author upon request.

\section{Conflicts of Interest}

The authors declare that they have no conflicts of interest regarding the publication of this paper.

\section{Acknowledgments}

The authors acknowledge the National Key Research and Development Program of China (Grant no. 2018YFC1508604) and the National Natural Science Foundation of China (Grant no. 51778210) for the financial support.

\section{References}

[1] J. D. Rice and J. M. Duncan, "Findings of case histories on the long-term performance of seepage barriers in dams," Journal of Geotechnical and Geoenvironmental Engineering, vol. 136, no. 1, pp. 2-15, 2010.

[2] K. S. Richards and K. R. Reddy, "Critical appraisal of piping phenomena in earth dams," Bulletin of Engineering Geology and the Environment, vol. 66, no. 4, pp. 381-402, 2007.

[3] J. Danka and L. M. Zhang, "Dike failure mechanisms and breaching parameters," Journal of Geotechnical and Geoenvironmental Engineering, vol. 141, no. 9, Article ID 4015039, 2015.

[4] T. C. Kenney and D. Lau, "Internal stability of granular filters," Canadian Geotechnical Journal, vol. 22, pp. 245-325, 1985.

[5] R. J. Fannin and R. Moffat, "Observations on internal stability of cohesionless soils," Géotechnique, vol. 56, no. 7, pp. 497-500, 2006.

[6] L. M. Zhang and Q. Chen, "Seepage failure mechanism of the Gouhou rockfill dam during reservoir water infiltration," Soils and Foundations, vol. 46, no. 5, pp. 557-568, 2006.

[7] C. F. Wan and R. Fell, "Assessing the potential of internal instability and suffusion in embankment dams and their foundations," Journal of Geotechnical and Geoenvironmental Engineering, vol. 134, no. 3, pp. 401-407, 2008.

[8] B. Indraratna, V. T. Nguyen, and C. Rujikiatkamjorn, "Assessing the potential of internal erosion and suffusion of granular soils," Journal of Geotechnical and Geoenvironmental Engineering, vol. 137, no. 5, pp. 550-554, 2011.

[9] R. Moffat, R. J. Fannin, and S. J. Garner, "Spatial and temporal progression of internal erosion in cohesionless soil," Canadian Geotechnical Journal, vol. 48, no. 3, pp. 399-412, 2011. 
[10] K. S. Richards and K. R. Reddy, "Experimental investigation of initiation of backward erosion piping in soils," Géotechnique, vol. 62, no. 10, pp. 933-942, 2012.

[11] A. W. Skempton and J. M. Brogan, "Experiments on piping in sandy gravels," Géotechnique, vol. 44, no. 3, pp. 449-460, 1994.

[12] L. N. Reddi, I. Lee, and M. V. S. Bonala, "Comparison of internal and surface erosion using flow pump test on a sandkaolinite mixture," Geotechnical Testing Journal, vol. 23, no. 1, pp. 116-122, 2000.

[13] D. Marot, F. Bendahmane, F. Rosquoët, and A. Alexis, "Internal flow effects on isotropic confined sand-clay mixtures," Soil and Sediment Contamination: An International Journal, vol. 18, no. 3, pp. 294-306, 2009.

[14] H. H. Nguyen, D. Marot, and F. Bendahmane, "Erodibility characterisation for suffusion process in cohesive soil by two types of hydraulic loading," La Houille Blanche, vol. 6, no. 6, pp. 54-60, 2012.

[15] T. Yuan, Z. M. Jiang, D. Q. Liu, and X. H. Xiong, "Experiment on the seepage damage coarse grain soil," Rock and Soil Mechanics, vol. 39, no. 4, pp. 1311-1316, 2018, in Chinese.

[16] D. S. Chang and L. M. Zhang, "A stress-controlled erosion apparatus for studying internal erosion in soils," Geotechnical Testing Journal, vol. 34, no. 6, pp. 579-589, 2011.

[17] D. S. Chang and L. M. Zhang, "Critical hydraulic gradients of internal erosion under complex stress states," Journal of Geotechnical and Geoenvironmental Engineering, vol. 139, no. 9, pp. 1454-1467, 2013.

[18] L. Ke and A. Takahashi, "Strength reduction of cohesionless soil due to internal erosion induced by one-dimensional upward seepage flow," Soils and Foundations, vol. 52, no. 4, pp. 698-711, 2012.

[19] L. Ke and A. Takahashi, "Experimental investigations on suffusion characteristics and its mechanical consequences on saturated cohesionless soil," Soils and Foundations, vol. 54, no. 4, pp. 713-730, 2014.

[20] J. L. Sherard, L. P. Dunnigan, and J. R. Talbot, "Basic properties of sand and gravel filters," Journal of Geotechnical Engineering, vol. 110, no. 6, pp. 684-700, 1984.

[21] U. E. Shamy and F. Aydin, "Multiscale modeling of floodinduced piping in river levees," Journal of Geotechnical and Geoenvironmental Engineering, vol. 134, no. 9, pp. 1385-1398, 2008.

[22] D. Muir Wood, K. Maeda, and E. Nukudani, "Modelling mechanical consequences of erosion," Géotechnique, vol. 60, no. 6, pp. 447-457, 2010.

[23] P.-Y. Hicher, "Modelling the impact of particle removal on granular material behaviour," Géotechnique, vol. 63, no. 2, pp. 118-128, 2013.

[24] Z. L. Wu, X. Y. Zhu, S. W. Jiang, H. S. Liu, and Y. F. Deng, "Difference and mechanism analysis on percolation behavior of pure clay and sand-clay mixtures," Journal of Southwest University. National, vol. 45, no. 2, pp. 376-381, 2015, in Chinese.

[25] M. Fukue, S. Okusa, and T. Nakamura, "Consolidation of sand-clay mixtures," Testing and Evolution, vol. 892, pp. 627-641, 1986.

[26] Y. Watabe, K. Yamada, and K. Saitoh, "Hydraulic conductivity and compressibility of mixtures of Nagoya clay with sand or bentonite," Géotechnique, vol. 61, no. 3, pp. 211-219, 2011.

[27] C. Boutin, G. Kacprzak, and D. Thiep, "Compressibility and permeability of sand-kaolin mixtures. Experiments versus non-linear homogenization schemes," International Journal for Numerical and Analytical Methods in Geomechanics, vol. 35, no. 1, pp. 21-52, 2011.

[28] N. A. Shayea, "Effect of clay and moisture content on the behavior of remolded unsaturated soils," Engineering Geology, vol. 62, no. 4, Article ID 319342, 2000.

[29] K. K. Tripathi and B. V. S. Viswanadham, "Evaluation of the permeability behaviour of sand-bentonite mixtures through laboratory tests," Indian Geotechnical Journal, vol. 42, no. 4, pp. 267-277, 2012.

[30] K. Rajesh, U. Jain, and C. Kothyari, "Influence of cohesion on suspended load transport of non-uniform sediments," Journal of Hydraulic Research, vol. 48, no. 1, pp. 33-43, 2010.

[31] F. Bendahmane, D. Marot, and A. Alexis, "Experimental parametric study of suffusion and backward erosion," Journal of Geotechnical and Geoenvironmental Engineering, vol. 134, no. 1, pp. 57-67, 2008.

[32] S. Thevanayagam, "Effect of fines and confining stress on undrained shear strength of silty sands," Journal of Geotechnical and Geoenvironmental Engineering, vol. 124, no. 6, pp. 479-491, 1998.

[33] C. Y. Heng and Y. H. Qiu, "Experimental research on influence of grain size gradation on anti-liquefaction characteristics of clayey sand with montmorillonite," Journal of China University of Mining \& Technology, vol. 31, no. 2, pp. 138-141, 1998, in Chinese. 